\title{
Can Foreign Aid Create an Incentive for Good Governance? Evidence from the Millennium Challenge Corporation
}

Doug Johnson and Tristan Zajonc

CID Graduate Student and Postdoctoral Fellow

Working Paper No. 11, April 2006

(C) Copyright 2006 Doug Johnson, Tristan Zajonc, and the

President and Fellows of Harvard College
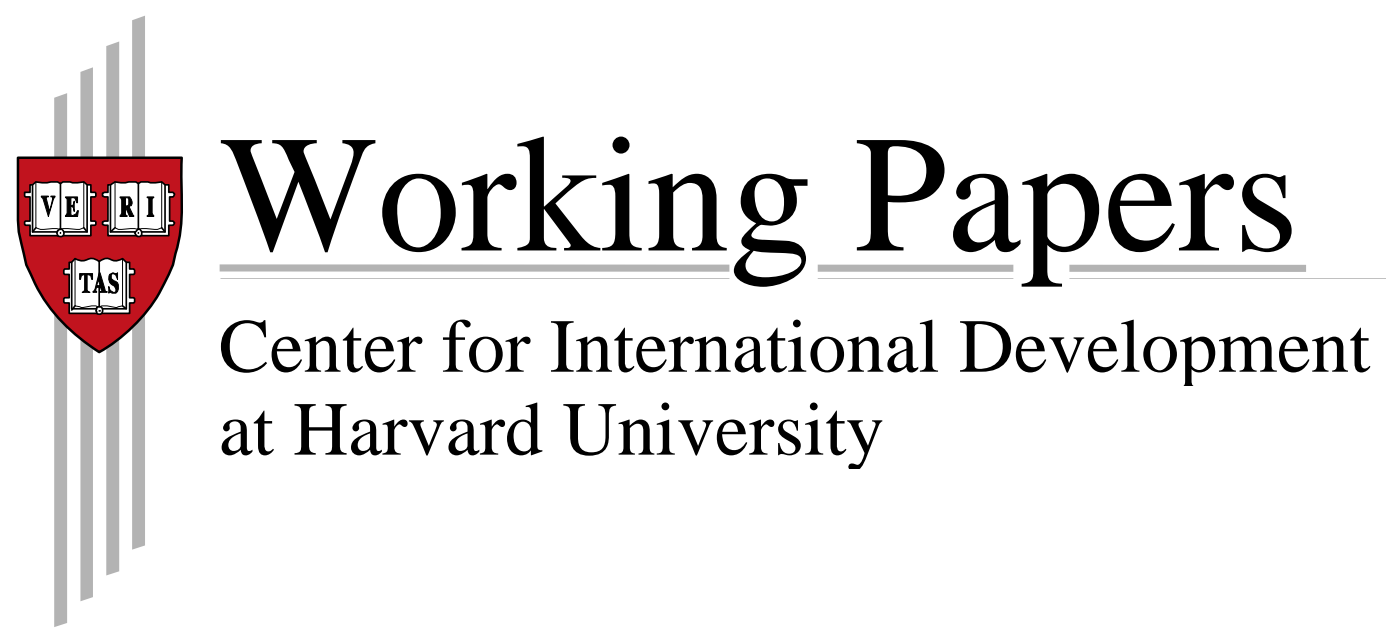


\title{
Can Foreign Aid Create an Incentive for Good Governance? Evidence from the Millennium Challenge Corporation
}

\author{
Doug Johnson \\ Harvard University \\ Tristan Zajonc* \\ Harvard University
}

April 11, 2006

\begin{abstract}
The Millennium Challenge Corporation (MCC) awards aid to countries that perform well on a set of independently compiled governance indicators. Proponents of this new form of aid argue that 1) aid will be more effective when given to well-governed countries and 2) countries will respond to such rewards by pursuing sound policies. This paper is the first systematic attempt to evaluate the second hypothesis. By exploiting discontinuities in the MCC rules and reform patterns before and after the MCC was created, we are able to estimate the MCC incentive effect. Even though the MCC is still in its infancy, we find substantial evidence that countries respond to $\mathrm{MCC}$ incentives by improving their indicators. Controlling for general time trends, potential recipients of MCC funds improve 25 percent more indicators after the MCC was created than before it. While still too early to make a final assessment, a range of specifications yield similar results. We do not find any corresponding increase in growth rates.
\end{abstract}

\section{Introduction}

In March, 2004, two years after being proposed by President Bush, the Millennium Challenge Corporation (MCC) began operations. The MCC represents perhaps the most significant shift in US foreign aid policy since President Kennedy signed the Foreign Assistance Act of 1961 that separated military and non-military aid and established the U.S. Agency for International Development (USAID). Unlike traditional aid organizations, the MCC is designed not to deliver aid to a broad collection of impoverished nations, but rather to focus selectively on those countries whose governments are deemed most committed to ruling justly, investing in their citizens, and promoting economic freedom - as measured by a set of objective and transparent governance indicators.

*E-mail address: doug_johnson@ksg06.harvard.edu, tristan_zajonc@ksg06.harvard.edu. We are indebted to Brad Parks of the MCC for providing a consolidated version of the MCC data and for answering many questions we had. We are grateful also for discussions with Alberto Abadie, Jishnu Das, Asim Khwaja and Michael Walton and feedback from seminar participants at the Kennedy School. 
Proponents of this new form of aid argue that 1) aid will be more effective when given to wellgoverned countries and 2) countries will respond to such rewards by pursuing sound policies. This paper evaluates the second claim. ${ }^{1}$ We seek to answer the question: have countries improved their performance on the MCC governance indicators in hopes of receiving MCC funds? This paper is the first systematic attempt to evaluate the MCC incentive effect. By virtue of the MCC's novel structure, this paper is also, to our knowledge, the first evaluation of ex post rewards for reform that are based on objective measures of performance. While ex ante conditionality has been studied previously in relation to World Bank and IMF loans, the MCC awards aid solely based on past performance. ${ }^{2}$

We estimate the MCC effect by exploiting unique features of the MCC rules and reform patterns before and after the MCC was created. While not random, the MCC selection process is based on transparent and discontinuous rules. When combined with time-series variation, this discontinuity in the selection of potential recipient countries allows us to estimate the MCC incentive effect using a simple difference-in-differences (DD) and difference-in-difference-in-differences (DDD) strategy. However because of the limited number of observations inherent to cross-country analysis, we cannot estimate the MCC incentive effect solely based on the discontinuities. Nevertheless, borrowing from the intuition of regression-discontinuity design, we report estimates of the MCC effect using a small number of countries near the MCC rule threshold. This strategy further weakens the already modest identifying assumptions of our DD and DDD estimates and gives us added confidence in our results.

Even though the MCC is still in its infancy, we find substantial evidence that countries improve their indicators because of the MCC. Candidate countries - countries that are potential recipients of MCC funds - are more likely to improve their performance on the indicators used by the MCC and display greater absolute increases on these indicators. Overall, candidate countries reform approximately 25 percent more indicators after the creation of the MCC than before it, compared to poor non-candidate countries. On nine of the thirteen indicators for which data is available, candidate countries are more likely to improve their indicators after the MCC was created, controlling for general time trends using poor non-candidate countries. For some indicators the likelihood of reform is substantially higher. Our best estimates suggest that over 25 percent of candidate countries improve their civil liberties, education expenditure, health expenditure, immunization rate, inflation and regulatory quality indicators because of the MCC. But not all of our results are positive. Some estimates of the MCC incentive effect, particularly those that use measures of reform magnitude rather than likelihood, are negative. Nevertheless, these negative estimates generally are smaller and less statistically significant than the positive estimates. The overall results suggest that the MCC incentive effect is real.

While our results suggest countries are improving their indicators because of the MCC, we make

\footnotetext{
${ }^{1}$ The first claim has inspired an immense and conflicted literature. Much of the recent literature debates the results of Burnside and Dollar (2000) who argue that aid is more effective in countries with good policy environments.

${ }^{2}$ There are a few smaller efforts to adopt performance-based aid allocation systems. The World Bank, for example, uses the Country Policy and Institutional Assessment (CPIA) score to make some funding decisions. These efforts, however, are neither as stringent nor as large as the MCC (Radelet, 2006).
} 
no claim as to what impact, if any, this has on long run growth or poverty rates. So far, we find no effect. Growth is higher in the years following the creation of the MCC, but this increase is similar for candidate countries and poor non-candidate countries. This may be due to a time lag in the effect of policy on growth, or it may be real. More research, and probably more time, is needed to explore these possibilities.

An important concern, expressed by a number of MCC observers, is that countries may artificially manipulate their MCC indicators. ${ }^{3}$ Such manipulation would directly affect the policy implications of our results. However, we find most of the indicators to be sufficiently robust to the threat of manipulation to conclude that the majority of the majority of improvements observed are due to changes in actual policies. While the governance indicators utilized by the MCC are imperfect measures of underlying policies, we believe wholesale manipulation is an unlikely explanation for our results.

The statistical and anecdotal evidence suggests that when foreign aid is given contingent on past performance, countries respond. This evidence, while suggestive, is also preliminary. In this paper, we only study the first two years of the MCC, a period too short to draw firm conclusions. Moreover, the MCC continues to evolve, adding and dropping indicators, and introducing new classifications for countries that are eligible for aid. Our results may not be applicable to the MCC of the future. Nevertheless, the first two years of the MCC provide a rare opportunity to study whether foreign aid can create an incentive for good governance. If our estimates are correct, a shift in the budget of aid agencies toward performance-based aid may be warranted.

This paper is organized as follows: Section 2 summarizes the main justifications that led to the MCC's formation, the way the MCC distributes aid, and the current status of the MCC. Section 3 discusses the plausibility of the MCC incentive effect and some anecdotal evidence that supports our subsequent results. Section 4 outlines the our data and empirical strategy. Section 5 presents our results. Section 6 concludes.

\section{MCC Background}

\subsection{Justifications for the MCC}

In March of 2002, before an audience at the headquarters of the Inter-American Development Bank, President Bush announced two major changes to his administration's international aid policy. First, the president committed to increasing the US budget for overseas development assistance by $\$ 5$ billion annually - the largest one time increase in overseas assistance in over forty years. Second, the president announced the creation of a new government agency, the Millennium Challenge Corporation (MCC), to oversee the distribution of these funds.

The creation of the MCC represented more than a bureaucratic schism. In his speech announcing

\footnotetext{
${ }^{3}$ Andvig (2004), Sautet, Hooks and Rothschild (2005), and Radelet (2002) all express varying degrees of concern about the potential for manipulation.
} 
the MCC, President Bush outlined the fundamental difference between the principles underlying the MCC and those of traditional aid agencies. Rather than distributing aid based on need or strategic interests, the MCC would selectively help those countries that were deemed committed to governing justly, investing in their citizens, and promoting economic freedom - as measured by a set of sixteen objective, transparent, and independently compiled indicators. Bush cited two reasons for this approach. First, because MCC funds would only go to the best governed poor countries, the funds would be better spent. Second, by basing aid on past performance, the MCC would create an incentive for good governance. In the words of President Bush, the MCC would "reward nations that root out corruption, respect human rights, and adhere to the rule of law."4

The first of these justifications, that aid is better spent in countries with sound policy environments, received support not only from the long-held intuition of many development professionals but also from timely empirical research. In an extremely influential paper, Burnside and Dollar (2000) used historical data on aid, growth, and various measures of governance to attempt to show that aid, when disbursed to countries that are governed effectively, causes growth. As Burnside and Dollar (2000) write, "aid has a positive impact on growth in developing countries with good fiscal, monetary, and trade policies but has little effect in the presence of poor policies." 5 This finding provided a vital justification for the MCC's selectivity. It was also a finding proponents of the MCC latched on to. As stated on the White House website, the MCC "recognizes that economic development assistance can be successful only if it is linked to sound policies in developing countries." 6

More recently the conclusion of Burnside and Dollar (2000) has been questioned. ${ }^{7}$ Perhaps the most persuasive critique is by Easterly, Levine and Roodman (2004). They use the same specification as Burnside and Dollar (2000) but include additional data. With this new data, they find that the crucial interaction term between aid and policies is insignificant. In a reply, Burnside and Dollar (2004b) remain hopeful, concluding, "aid directed to countries with good policies will be more likely to produce good results." 8 While the empirical literature is inconclusive, the belief that aid given to well governed countries will be better spent remains a primary justification for the MCC's structure.

The second hypothesis, that aid can create an incentive for countries to pursue good governance, also figured prominently in policy discussions leading up to the MCC's creation. ${ }^{9}$ Perhaps because the Burnside and Dollar (2004b) results are no longer considered robust, this justification has recently been given increasing prominence. In his speech outlining his vision for the MCC, newly installed MCC

\footnotetext{
${ }^{4}$ Bush, George W., March 15th, 2002. Contents of Speech Given at Inter-American Development Bank. http://www.whitehouse.gov/news/releases/2002/03/20020314-7.html

${ }^{5}$ Burnside and Dollar (2000, p. 847)

${ }^{6} \mathrm{http}: / /$ www.whitehouse.gov/infocus/developingnations/

${ }^{7}$ See, for example, Hansen and Tarp (2000), Hansen and Tarp (2001), Dalgaard and Hansen (2001), Guillaumont and Chauvet (2001), Lensink and White (2001),Easterly (2003), and Easterly, Levine and Roodman (2004).

${ }^{8}$ Burnside and Dollar (2004a) reexamine the relationship between aid, growth, and policies using data from the 1990s. Using this new data, they find evidence that supports their original conclusion that aid is more effective in a good policy environment.

${ }^{9}$ Eviatar, Daphne, July 26th, 2003. "Do Aid Studies Govern Policies or Reflect Them.” The New York Times.
} 
CEO John Danilovich expressed the belief that "the only way that [the MCC] can be transformational is to incentivize these countries to make the reforms that are necessary." 10 Likewise, Sautet, Hooks and Rothschild (2005, p. 6) argue that MCC compacts "could turn out to be far less important than the policy changes countries undertake to qualify for MCA assistance."

The belief that the MCC will alleviate poverty by creating an incentive for countries to pursue better policies, is based more on theory than evidence. Just as individuals respond to incentives, proponents argue, so too do countries. The theoretical focus is not because the empirical evidence does not support the claim, but rather because there was no empirical evidence from which to draw. While the World Bank and the other international financial institutions have long attempted to link aid to policy, these institutions do so mainly by placing conditions on the use of money after its disbursement rather than selecting potential recipients on the basis of their policies before disbursement. In the case of the World Bank, future tranches of loans may, in theory, be cancelled if governments fail to meet the conditions specified in the original disbursement. But the World Bank has opted to enforce this rule only once - the case of Senegal in the 1980s. ${ }^{11}$

Even though many organizations claim to support countries with good policies, this does not appear to be true. Alesina and Weder (2002) find that there is no relationship between bilateral and multilateral aid and the corruption level of recipient countries. For the United States they actually find a positive relationship between corruption and aid. This stands in stark contrast to the MCC allocation rule; countries cannot receive MCC aid unless they are above the median on the control of corruption indicator. Burnside and Dollar (2000) also examine the determinants of aid flows. They find only a weak association between international aid flows and policy.

\subsection{Aid Distribution Methodology}

To receive funding from the MCC, a country must meet four independent criteria:

1. It must have a GNI per capita under the upper limit for receipt of loans from the World Bank's International Development Association or be listed as a lower middle income country by the World Bank on its most recent World Development Report;

2. It must not be restricted from receiving US aid by Congressional statute; ${ }^{12}$

3. It must perform sufficiently well on a set of sixteen independently compiled governance indicators; and

4. It must submit a compact proposal deemed worthy by the MCC's board of directors.

\footnotetext{
${ }^{10}$ John J. Danilovich (2006). CGD Benin compact signing transcript.

${ }^{11}$ Mosley, Hodgson and Verschoor (2004).

${ }^{12}$ This list includes countries with poor extremely poor human rights records and those officially designated as state sponsors of terror by the State Department. In 2005, the countries barred from receiving development assistance by Congress were Burma, Burundi, Cambodia, C.A.R., Cote d'Ivoire, Cuba, Equatorial Guinea, Iraq, North Korea, Liberia, Somalia, Sudan, Syria, Uzbekistan and Zimbabwe.
} 
These selection criteria are applied in stages. First, all countries which meet the first and second criteria are identified as candidate countries by the MCC and divided into two groups. Those countries with a GNI per capita under the IDA limit - \$1575 in 2004 - form the largest group, the "Low Income Category." Countries with a GNI per capita above the IDA limit but which have been identified as lower middle income countries by the World Bank form the second group, the "Low Middle Income Category." This second group was only added by the MCC in FY2006 and is largely ignored for that reason in the analysis that follows.

In the second stage, the performance of each candidate country on the sixteen governance indicators (Table 1) is gauged against the performance of income group peers. Although transparent, the process for determining eligibility is slightly complicated. The sixteen indicators are split into three distinct groups: encouraging economic freedom, ruling justly, and investing in people. To be eligible, a country must attain a score better than the median value of all countries in its income group (including countries which are statutorily restricted from receiving US development assistance) on the control of corruption indicator and on at least half of the indicators in each of the three groups. Missing indicator values are considered worse than the median. The one exception to the median rule is inflation; countries must have inflation rates below 15 percent. In addition to the objective eligibility rules, the MCC reserves the right to exercise its own discretion in determining the final list of countries which pass this stage. In the past, the MCC has used this discretionary power sparingly to exclude countries that, for political reasons, are deemed inappropriate recipients of US aid such as China, India, and Bhutan and to include countries which are very close to qualifying.

Countries which pass through these first two stages of selection are deemed eligible for MCA funds and are invited by the organization to submit funding proposals. Submitted proposals are reviewed by the MCC and those found suitable are then approved and signed by the MCC's board of directors along with the leaders of the country and turned into compacts - legally binding documents specifying the amount of aid to be given, the uses to which it will go, and the performance criteria that the country must meet in its use of the money. According to the MCC's stated guidelines, countries may submit proposals for any projects which are both growth enhancing and poverty reducing. ${ }^{13}$

In addition to this main channel for distributing development assistance, the MCC also distributes a limited portion of the funds appropriated to it (by law no greater than 10 percent of the total amount of MCA funds) to countries at or near the threshold for receiving funds with the purpose of improving these countries' scores on their MCA indicators. Access to funds through this program, known as the "Threshold Program," is solely at the discretion of the MCC. Due to the relatively small amount of funds distributed through this program to date - only two threshold projects have been approved for a total of $\$ 34$ million - and its limited capacity to incentivize reform, we exclude this program from our analysis.

\footnotetext{
${ }^{13}$ Some observers, such as Kurlantzick (2006), have accused the MCC of harboring a pro-business bias in the process for determining which proposals are approved.
} 
Since the MCC began operations, several relatively minor changes have been made to the selection methodology. By far the most significant changes involve the addition and exclusion of indicators. In fiscal years 2005 and 2006, country credit rating and primary education completion rate were replaced by the cost of starting a business and girls primary education completion rate. In its most report on its recipient selection methodology, the MCC indicated that although it is unlikely to alter the underlying method behind the selection process, it will almost surely add or drop a few specific indicators as new data becomes available. Two areas in which the MCC has identified a need for indicator improvement are those for natural resource management and women and children's health. ${ }^{14}$ Because such changes make analysis of the incentive effect more difficult, we consider only the set of most recent indicators.

\subsection{Funding}

In his original speech outlining the creation of the MCC, President Bush called for $\$ 5$ billion to be allocated to the organization for disbursement each year. This sum, if agreed to by Congress, would have represented a nearly 25 percent increase in the total amount of development assistance provided by the US each year. ${ }^{15}$ While the actual amounts appropriated by Congress for fiscal years 2004, 2005 and 2006 were only $\$ 1$ billion, $\$ 1.5$ billion and $\$ 1.75$ billion respectively, this amount still represents a substantial increase in the overall amount of US development assistance. ${ }^{16}$ For fiscal year 2007, President Bush has requested $\$ 3$ billion in funding for the MCA. ${ }^{17}$

Despite being allocated almost $\$ 1$ billion by Congress and certifying sixteen countries as eligible to receive MCA funds, the MCC signed no compacts with any of the countries in its first year of operation. In its second year, amid criticism that it was too slow ramping up, the MCC signed five separate compacts incurring a total grant obligation of over $\$ 900$ million over the next five years. The MCC also approved, but did not sign, four additional compacts totaling $\$ 1.5$ billion. While the total value of existing compacts is relatively modest compared to the envisioned allocation, this is largely a temporary concern. Under the terms of the Millennium Challenge Act, unallocated funds which the MCC does not commit to spending in the fiscal year for which the funds are appropriated may be used in subsequent years. ${ }^{18}$

\footnotetext{
${ }^{14} \mathrm{MCC}$, 2006. "Report on the Criteria and Methodology for Determining the Eligibility of Candidate Countries for Millennium Challenge Account Assistance in FY 2006" http://www.mca.gov/about_us/congressional_reports/FY06_Criteria_Methodology.pdf

${ }^{15}$ CRS Report for Congress, 2005, "Foreign Aid: An Introductory Overview of US Programs and Policy", http://usinfo.state.gov/usa/infousa/trade/files/98-916.pdf, p. 18.

${ }^{16}$ Government Accounting Office, 2005, "Millennium Challenge Corporation: Progress Made on Key Challenges in First Year of Operations", http://www.gao.gov/new.items/d05625t.pdf, p. 2

${ }^{17}$ USA Today, February 7th, 2005. "Budget Plan at a Glance." http://www.usatoday.com/news/washington/2005-02-07budget-glance_x.htm

${ }^{18}$ Government Accounting Office, 2005, "Millennium Challenge Corporation: Progress Made on Key Challenges in First Year of Operations", http://www.gao.gov/new.items/d05625t.pdf , p. 8.
} 


\subsection{Is an MCC Incentive Effect Plausible?}

Prudence dictates that before investigating the evidence for and against the existence of a MCC incentive effect we verify that an incentive effect is indeed plausible. For the MCC effect to pass the basic litmus test of plausibility 1) the size of the reward must be large enough that it is within the realm of possibility that countries might modify their behavior to gain access to the funds and 2) the probability of receiving the reward must be sufficiently high that countries deem the possibility of receiving the award more than just a lottery.

The MCA easily passes these two hurdles. As shown in Figure 2, MCA funds have caused a substantial increase in government revenues for those countries already awarded compacts. In Georgia, Benin, and Cape Verde, MCA aid accounts for more than a 10 percent increase in total government expenditure and 20 percent increase in total aid, each year the compact covers. The MCC also ranks as one of the top ten donors in all of the six countries that have signed compacts (Table 3 ). Furthermore, with six countries having signed compacts with the MCC out of a total candidate field of 98, the odds of gaining access to MCA funds, while still modest, appear high enough to merit the attention of candidate countries.

\subsection{Anecdotal Evidence of an MCC Incentive Effect}

In the two years since the creation of the MCC, limited anecdotal evidence has emerged to indicate that countries are indeed modifying their behavior in the hopes of gaining access to MCA funds. Some of the anecdotal evidence that supports the MCC incentive hypothesis includes:

1. In Armenia, presidential contender Vartan Oksanian referred to the MCA funds when calling for increased openness in the upcoming election stating, "We are now in a situation where any step away from democratization and a repeat of electoral fraud would have an economic cost. And I can name that cost: 235 million dollars." 19

2. According to the MCC website, the minister of finance for Bangladesh, Saifur Rahman, pointed to his country's exclusion from the list of MCC eligible countries as one of the heavy consequences for its high level of corruption. ${ }^{20}$

3. Representatives of the countries themselves have identified the MCA funds as a principal rationale behind reforms. According to Simeon Djankov, author of the World Bank's Doing Business report from which two of the MCA indicators are drawn, 80 percent of countries that have carried reforms to make it easier to start new businesses claimed to have done so for the purpose of potentially receiving MCA funds.

\footnotetext{
${ }^{19}$ Daneilyan, Emil. December 29th, 2005. “Oksanian Warns of 'Economic Cost' of Vote Rigging” Armenia Liberty website. http://www.armenialiberty.org/armeniareport/report/en/2005/12/119FDE16-01E6-4A4A-BFDD-F9F0261398F7.ASP

${ }^{20}$ MCC. 2005. "Millennium Challenge Account, Already Paying Dividends," http://www.mca.gov/public_affairs/fact_sheets/Apr05_fact_sheet.shtml
} 
While the anecdotal evidence presented above demonstrates that countries are in fact taking notice of the MCC, this is far from conclusive evidence that the MCC has caused candidate countries to reform. The problems inherent in relying on anecdotal evidence are illustrated by the claim, made in the MCC's 2005 report to Congress and elsewhere, that 80 percent of the reform on the "days to start of business" indicator for candidate countries can be attributed to the MCA. This claim arose from the World Bank's Doing Business report which asked countries directly for the reasons they were reforming their indicators. ${ }^{21}$ According the report's author, over 80 percent of candidate countries cited the MCC as a primary motivator for reform.

But there are several facts that cast doubt on whether the MCC is the true cause of the observed changes. Although between 2002 and 200484 percent of candidate countries for which this indicator was compiled reduced the number of days it takes to start a business, this reform trend was not limited to candidate countries. During the same time period, 64 percent of all non-candidate countries for which this indicator was compiled also improved their performance on this indicator. When we restrict our control group to non-candidate countries with GNI per capita below $\$ 3255$ (low and low-middle income countries) the share of countries which improved rises to 74 percent. And if we further refine our control group by eliminating countries prohibited by Congress from receiving MCA funds, whose ranks include North Korea and Cuba, this figure rises to 81 percent - a number nearly equal to that for candidate countries.

The fact that non-candidate countries, who by definition have no MCC related incentive to improve their indicators, were almost as likely to reform as candidate countries casts doubt on the claim that $80 \%$ of reform in candidate countries was caused by the MCC incentive effect, even if countries report the MCC as a major motivator. Our empirical analysis attempts to improve upon the anecdotal evidence by comparing candidate countries to a reasonable control group and using reform patterns from before and after the MCC was created. As the days to start a business example makes clear, finding an adequate control group is of paramount importance.

This cursory reanalysis of the MCA's claim regarding the days to start a business indicator illustrates the difficulty in relying on anecdotal evidence to make causal statements. But while bold claims should be questioned and caution is warranted, this is also not enough evidence to conclude that there is no MCC effect. Too little systematic empirical work has been done to draw any firm conclusions. This paper seeks to fill this void.

\footnotetext{
${ }^{21}$ This variable is not included in the publicly available version of the Doing Business report. However, the report's author, Simeon Djankov, confirmed this result to the authors in an email.
} 


\section{Data and Empirical Strategy}

\subsection{Data}

The MCC uses 16 indicators drawn from a number of independent sources. Table 1 describes these indicators and their sources. Our main dataset consists of the $16 \mathrm{MCC}$ indicators and basic country data from the World Bank's World Development Indicators. While the MCC indicators are selected in part for the breadth of coverage, not all indicators cover all countries. There is also considerable variation in the length of the time-series for each variable. For example, Freedom House's political rights and civil liberties indicators are available back to 1973 and are updated yearly. The World Bank Institute indicators, by comparison, are only available back to 1996 and are updated every two years. And the cost of starting a business indicator is only available back to 2003, precluding any analysis of reform patterns before the MCC was created.

In addition to covering different sets of countries and different time periods, the MCC indicators are also expressed on different scales. An improvement is not always an increase in the indicator. And the magnitude of change cannot be readily compared. Table 2 provides summary statistics for the indicators for low and low-middle income countries and indicates the direction of an improvement.

For our analysis, we drop a large number of observations. First, we exclude all countries with GNI per capita above $\$ 3255$ - the MCC definition of lower-middle income. Second, we limit ourselves to the three years $-2000,2002$, and 2004. Although we did not restrict the sample during our preliminary analysis of the data, these restrictions limit the sample to more comparable countries and to a time period directly relevant to the analysis of the MCC. We use two year differences to avoid the possibility of serial correlation influencing our estimated standard errors (Bertrand, Duflo and Mullainathan, 2004) and because some variables are only available biannually. Because most data is not available for 2005, we do not include this year. We also do not include old indicators than have been replaced.

With these restrictions, we are left with 102 countries. Because of missing data, however, far fewer countries are available for many indicators. In addition, we generally exclude countries that are statutorily restricted from receiving assistance. These countries neither have an incentive to improve their indicators nor can be used as a control for countries that do.

\subsection{Empirical Strategy}

Any estimation of the MCC incentive effect is hampered by the fundamental program evaluation problem; once the MCC was established, the world without it became forever hidden. In absence of the true counterfactual outcome, the task of the program evaluator becomes finding an adequate control group.

The design and implementation of the MCC allows for a number of empirical strategies to test for the hypothesized MCC incentive effect. These strategies rely on the following three facts: 
1. There can be no MCC effect before 2002, the year the future creation of the MCC was announced.

2. The MCC candidate cutoff is discontinuous function of per capita GNI.

3. The MCC eligibility cutoff is a discontinuous function of the indicator levels.

The consequences of these facts can be explored independently or simultaneously. Independent approaches are the most straightforward. Comparing the average change or likelihood of reform in candidate countries between 2002 and 2004 and between 2000 and 2002, for example, provides an estimate of the MCC effect under the strong assumption that time trends are the same in both periods, absent the MCC. Likewise, comparing post-MCC changes in candidate countries to non-candidate countries provides an estimate of the incentive effect under the assumption that income - the basic difference between candidate and non-candidate countries - does not affect the rate or likelihood of reform.

\subsubsection{Difference-in-Differences}

The strict identifying assumptions just outlined can be relaxed considerably by combining approaches. The simultaneous approach makes use of variation across time and between candidate and noncandidate countries to make the "control" more credible. In the combined approach, the question becomes: are candidate countries more likely to reform between 2002 and 2004 than between 2000 and 2002, controlling for any change in time trends using the reform patterns of poor non-candidate countries? Depending on the measure of outcome - a rate of reform or indicator level - this can be viewed as a difference-in-difference (DD) or difference-in-difference-in-differences (DDD) estimate; the estimate is based on a triple difference that subtracts any fixed country effects (the first difference), any fixed time trends (the second difference), and any change in time trends (the third difference).

Assuming the outcome is the indicator level, and suppressing any notation for country, we can write the DDD estimator as

$$
\begin{aligned}
D D D_{j}^{1}= & D D_{j}^{1}=E\left[\left(\left(Y_{j, 2004}^{T}-Y_{j, 2002}^{T}\right)-\left(Y_{j, 2004}^{C}-Y_{j, 2002}^{C}\right)\right)\right. \\
& \left.-\left(\left(Y_{j, 2002}^{T}-Y_{j, 2000}^{T}\right)-\left(Y_{j, 2002}^{C}-Y_{j, 2000}^{C}\right)\right)\right]
\end{aligned}
$$

where $E[\cdot]$ is the expectation, $Y_{j}$ is level of indicator $j,\{T, C\}$ are the treatment and control indicators and 2004, 2002 and 2000 are the pre- and post-MCC years. While other approaches are possible, our analysis defines the treatment group as candidate countries and the control group as poor noncandidate countries.

The DD and DDD labels are somewhat confusing because of the various choices for the outcome measure. Equation (1) is a DD estimate if we consider the reform rate, $Y_{t}-Y_{t-2}$, rather indicator 
level, $Y_{t}$, as the outcome. To maintain consistency, we use rates rather than levels as outcomes and refer to all our estimates as DD rather than DDD estimates.

Another outcome measure is whether a country improved an indicator. For this outcome, we can write a DD estimator of the MCC incentive effect for indicator $j$ as,

$$
\begin{aligned}
D D_{j}^{2} & =E\left[\left(1\left\{Y_{j, 2004}^{T}>Y_{j, 2002}^{T}\right\}-1\left\{Y_{j, 2004}^{C}>Y_{j, 2002}^{C}\right\}\right)\right. \\
-\left(1 \left\{Y_{j, 2002}^{T}\right.\right. & \left.\left.\left.>Y_{j, 2000}^{T}\right\}-1\left\{Y_{j, 2002}^{C}>Y_{j, 2000}^{C}\right\}\right)\right]
\end{aligned}
$$

where $1\{\cdot\}$ is an indicator function that takes the value of 1 if the expression is true and 0 if the expression is false. Because this outcome cannot be computed using one year of data, this estimate is best understood as a DD rather than DDD estimate.

A final outcome measure, that has the distinct advantage of combining all sixteen MCC indicators into one variable, is the fraction of indicators improved. ${ }^{22}$ We can write this measure as,

$$
P_{t}^{\{T, C\}}=\frac{1}{n} \sum_{j} 1\left\{Y_{j, t}^{\{T, C\}}>Y_{j, t-2}^{\{T, C\}}\right\}
$$

where $n$ is the number of indicators for which data exists, and the notation for countries is suppressed. Using this definition, the corresponding DD estimator becomes,

$$
D D^{3}=E\left[\left(P_{2004}^{T}-P_{2002}^{T}\right)-\left(P_{2004}^{C}-P_{2002}^{C}\right)\right] .
$$

The basic identifying assumption of these DD estimators is that absent the MCC the outcome would not have changed differentially for candidate and poor non-candidate countries between 2002 and 2004. This does not mean that the outcome must be equal. Candidate and non-candidate countries can, for example, have different rates of reform - given by the rates observed from 2000 to 2002. But any increase or decrease in these rates between 2002 and 2004 must be equal for candidate and poor non-candidate countries. Of course this assumption may be violated. This possibility, though, is less likely than violation of the assumptions made by the independent approaches and far less likely than the violation of the assumptions required to believe the existing anecdotal evidence.

\subsubsection{Regression-Discontinuity Design}

The strongest evidence - evidence based on the weakest assumptions - comes from DD estimates that include only countries near the candidacy rule discontinuity. The general approach of examining outcomes just above and below a discontinuous cutoff is known as regression-discontinuity (RD) design. RD design was first utilized by Thistlethwaite and Campbell (1960) who estimated the impact of National Merit Scholarships on college aspirations using the fact that scholarships are awarded only if the score exceeds a discrete threshold. By looking at students who scored just above and

\footnotetext{
${ }^{22}$ This measure was suggested to us by Jishnu Das.
} 
below this threshold and noting that any unobservables surely vary continuously around this point, Thistlethwaite and Campbell (1960) argued that differences in outcomes must be causally related to the National Merit Scholarship. Numerous other researches have used this approach to study a range of problems. $^{23}$ Hahn, Todd and der Klaauw (2001) provide a theoretical account of RD design that emphasizes the extremely weak identifying assumptions it requires.

With respect to the candidacy cutoff rule, the logic of RD design is straightforward. For 20022004 all countries not statutorily restricted from receiving aid with GNI per capita less than $\$ 1465$ qualified as MCA candidates; in 2005 this cutoff was raised to $\$ 1575$. The RD approach examines countries just above or below this income cutoff. If unobservable characteristics of countries vary continuously around these income thresholds then non-candidate countries just above the threshold are credible controls for candidate countries just below the cutoff. Furthermore, any small differences in income can be controlled for using a suitably flexible specification. But the appeal of RD design for estimating the MCC effect is not directly related to controlling for income. Rather, the appeal is that the candidacy threshold is unique to the MCC. Many programs assist countries' reform efforts and these programs may even do so uniquely to poor countries and uniquely during the 2002-2004 post-MCC period. However the only substantive difference between countries just above and below $\$ 1575$ is their MCC candidacy status. This is the great virtue of RD design.

The drawback of RD design is that it reduces significantly the number of observations available for analysis and thus the probability of obtaining statistically significant results. RD design typically relies on a large sample of individuals so that a reasonably sized sub-sample exists in the narrow band around the discontinuity. Since our analysis is carried at the country level, narrowing in on the discontinuity rapidly diminishes the sample size. There are only six countries, for example, within plus or minus $\$ 200$ of the $\$ 1465$ GNI per capita candidacy threshold. This limited sample makes it difficult to obtain statistically significant RD estimates for the MCC incentive effective based on one indicator and the candidacy threshold.

There are number of ways to improve the efficiency of RD estimates. First, the sample window can be enlarged. This increases the efficiency but risks bias if unobservables are correlated with the outcome of interest. While a Hausmann test comparing the narrow or wide window coefficients can rule out obvious inconsistency, the test does not prove the more efficient estimate is unbiased. A second approach is to test the coefficients for all the indicators jointly. Even if no individual regression yields statistically significant results, a joint test is more powerful. With this power, however, comes a loss of clarity; it is no longer possible to identify which particular indicator changes are significant. Still joint estimation and cross indicator tests provides a powerful technique to address the limited sample size inherent in cross-country analysis and RD design.

This procedure is complicated by potential covariance in the error terms of each regression. Such

\footnotetext{
${ }^{23}$ For example, Angrist and Lavy (1999) and Hoxby (2000) use the technique to study the effect of class sizes on learning, van der Klaauw (2002) estimates the effect of financial aid offers on college enrollment, and Jacob and Lefgren (2004) report results of a remedial education program.
} 
covariance occurs because general country shocks are unlikely to affect each indicator independently. A fiscal shock, for example, affects the education expenditure, health expenditure, fiscal debt indicators in similar ways. In the presence of such covariance, a joint test based on the independently computed standard errors is invalid. This problem can be overcome econometrically using Zellner's (1962) "seemingly unrelated regression" methodology. Zellner's (1962) technique explicitly allows for correlations in the disturbance terms of a system of (seemingly unrelated) regressions. This is precisely the problem faced when running separate regressions for each of the sixteen MCC indicators.

\subsubsection{Other Potential Strategies}

Although our primary analysis uses the MCC candidacy rule and variation across time, it is also possible to estimate the incentive effect using variation in the degree to which the MCC structure incents particular countries. This approach makes use of the third fact: that eligibility is a discontinuous function of the indicator levels. One possible hypothesis, for example, is that countries that only need one more indicator to qualify have a greater incentive to improve than countries that are already eligible or that have many deficient indicators. Defining two groups in this manner yields an estimate of the incentive effect, assuming that the two groups are equivalent but for the differences in eligibility status. While such an approach is promising, the complex form of the eligibility rule makes it difficult to form clear hypotheses about which countries have an incentive to reform and which set of countries form a credible control group. In a subsequent section, we briefly review the possibilities we explored and the difficulties we encountered. However because of the difficulties, we focus primarily on identifying the MCC effect through the use of the first two facts: the recent formation of the MCC and the discontinuous candidacy rule.

\section{Results}

\subsection{Basic Comparisons}

We begin our empirical analysis using the two simplest possible approaches: comparing the postMCC indicator performance of candidate countries with that of poor non-candidate countries, and comparing the pre- and post-MCC performance of candidate countries. If the outcome measure is thought of as the increase in reform, then these estimates are first differences using either poor noncandidate countries or the pre-MCC period as controls. The validity of this approach rests on strict assumptions. Nevertheless, describing the overall differences in behavior between candidate and poor non-candidates countries, and the pre- and post-MCC period, is a useful starting point.

Table 3 (column 6) and Figure 3 (panel 2) compare the post-MCC performance of candidate and poor non-candidate countries, using whether the indicator improved as the outcome measure. On eleven of the fourteen indicators for which data is available ${ }^{24}$, candidate countries are more likely to

\footnotetext{
${ }^{24}$ Data on the indicators for girls' primary completion rate and business start cost are missing for the year 2002.
} 
improve between 2002 and 2004 than non-candidate countries with per capita GNI below $\$ 3255$. On five indicators - political rights, civil liberties, health expenditure, education expenditure and immunization rate - candidate countries are at least twice as likely as poor non-candidate countries to improve their performance. And on the indicators where candidate countries are less likely to reform - voice and accountability, government effectiveness, and control of corruption - the differences are only a few percentage points. Compared the substantial positive differences these negative results are small.

In addition to providing some preliminary evidence in favor of an MCC effect, Figure 3 also illustrates the importance of comparing any improvement by candidate countries to a control, even if the control is less than ideal. Between 2002 and 2004, the fraction of countries that improved their days to start of business indicator - a change the MCC heralded in their report to Congress - is roughly equal for candidate and non-candidate control countries. While not conclusive, this strongly suggests that the MCC cannot claim full credit for the dramatic changes on the days to start a business indicator. $^{25}$

Comparing the pre- and post-MCC periods, rather than candidate and non-candidate countries, shows that on nine of thirteen indicators candidate countries are more likely to reform after the MCC was created than before it (Table 6). While the estimated differences are generally not as large as those between candidate and non-candidate countries, the fraction of indicators that improved is still greater after the MCC was created

One of the chief difficulties in digesting these results is that there are sixteen indicators, and a certain number of which will undoubtedly improve regardless of the MCC. Figure 4 presents the results of combing these indicators using the fraction of indicators a countries improves (Equation 3). Candidate countries improve a greater fraction of indicators both after the MCC was created than before, and than non-candidate countries

Using the average magnitude of change rather than the fraction of countries improving yields similar results. On eleven of fourteen indicators, candidate countries had a better mean rate of improvement between 2002 and 2004 than poor non-candidate countries (Table 4, Table 6). While several indicators fell on average, candidate countries often fell less. Candidate countries saw largest gains compared to poor non-candidate countries on the immunization rate indicator, with a difference of over 0.3 standard deviations. On eight of thirteen indicators, candidate countries had a greater average improvement during the MCC period than before it (Table 6). Some of the counterexamples, however, were dramatic. Inflation fell far more substantially on average between 2000 and 2002 than between 2002 and 2004. Likewise, trade policy reform was much more significant during the pre MCA time period. Even given these exceptions, the majority of indicators improved more substantially during the post-MCC time period.

\footnotetext{
${ }^{25}$ The dramatic reform of many of the Doing Business indicators is of considerable interest even if unrelated to the MCC incentive effect. Casual empiricism suggests that the indicators themselves may be galvanizing reform efforts. If this role of indicators is real, the MCC may have an additional benefit of publicizing indicators that have a galvanizing effect. We do not, however, explore this possibility here.
} 
There are, of course, a number of criticisms to using non-candidate countries controls. First, the non-candidate countries are by definition different than candidate countries. Even though we limit the non-candidate country sample to low and low-middle income countries, non-candidate countries are richer. Second, both the magnitude and likelihood of reform no doubt depend in large part on how reformed a country already is. Since candidate and control countries have different starting indicator levels, this may undermine the adequacy of the control group, at least without controlling for starting indicator levels.

It is also easy to criticize using the pre-MCC period as a control. Any causal interpretation of results that use this control relies on the assumption that candidate countries would have followed the exact same reform pattern in the two periods had the MCC not been formed. This assumption surely fails in principle; many events intervene over time. However, that these events tended to be positive during the MCC period does offer support in favor of the MCC incentive effect hypothesis.

\subsection{Difference-in-Differences Estimates}

The assumptions required in the preceding section can be weakened substantially by combining the two control strategies. Doing so yields a DD estimates of the MCC incentive effect (Equations 1,2, and 4). This DD strategy compares the relative pre- and post-MCC improvement for candidate countries, controlling for general time trends using the improvement of poor non-candidate countries. This is computed by comparing the relative likelihood of a candidate country reforming in the pre- and postMCC years and then subtracting this same difference in likelihood for poor non-candidate countries. Thus the reform pattern of poor non-candidate countries acts as a control for any general time trends that affect both groups of countries, such as an overall increase in reform between 2002 and 2004. The identifying assumption is thus that no policy besides the MCC affected only candidate countries, exclusively during the post-MCC time period.

The plausibility of the assumption that poor non-candidate countries adequately control for changing time trends is bolstered empirically by the fact that the difference between the change in candidate country indicator performance between 2000 and 2002 and the change in poor non-candidate country performance for the same time period is close to zero (Table 5, column 5). The small size of these pre-MCC DD estimates demonstrates that candidate countries and poor non-candidate countries displayed relatively similar trends in indicator performance prior to the formation of the MCC. This lends credence to the assumption that trends which are changing over time, and are not accounted for in the DD approach, do not impact our results significantly.

The DD estimates provide the strongest evidence yet of a MCC incentive effect. On nine of thirteen indicators, candidate countries are more likely to improve after the MCC was formed than before, controlling for general time trends using the reform pattern of poor non-candidate countries (Table 5, Table 6). Only the estimates for voice and accountability, government effectiveness, control of corruption, and trade policy are negative. And these negative results are all less then 10 percentage 
points. By comparison, on five indicators - civil liberties, education expenditure, health expenditure, inflation, and regulatory quality - the estimated difference in likelihood exceeds 25 percent. In other words, on these five indicators candidate countries are more than 25 percentage points more likely to reform after the MCC was created than before it, even after subtracting the difference in reform between these two time periods experienced by poor non-candidate countries.

The DD estimates using mean improvement yield somewhat different results. The estimate for trade policy is positive but the estimates for health expenditure is all negative. The majority of estimates are still positive. On nine of thirteen indicators, candidate countries improve more substantially during the post-MCC time, controlling for general time trends using reform patterns of poor noncandidate countries (Table 4, Table 6). While the estimates based on magnitudes are slightly weaker than those based on likelihoods, the results overall still support the MCC effect hypothesis.

Perhaps the easiest outcome measure to summarize is the fraction of indicators a country improves. Figure 4 and Table 7 show DD estimates using this measure (Equation 4). Between 2000 and 2002, the pre-MCC period, the average candidate and poor non-candidate country improves 41 percent of its indicators. This remarkably similar reform rate provides some additional comfort that poor noncandidate countries form a reasonable control group. By comparison, between 2002 and 2004, the post-MCC period, the average candidate country and poor non-candidate country improves 48 percent and 39 percent of its indicators, respectively. In order words, we estimate that candidate countries improve 25 percent (10 percentage points) more indicators because of the MCC. This estimate is statistically significant at the 5 percent level.

Although statistical significance is difficult to obtain with the small number of observations inherent to any evaluation of the MCC, the standard errors in Table 4 and 5 indicate that a number of the DD estimates for individual indicators are statistically significant. However this may be a data-mining artifact, since we have 16 indicators to choose from. Typically, a joint test F-test of the coefficients would be appropriate. But as discussed earlier, covariance across indicators makes a standard joint test inconsistent. To overcome this, Table 8 reports seemingly unrelated regression estimates of the MCC impact on the magnitude and likelihood of improvement. These estimates also control flexibly for $\log$ population, log income per capita and the lagged indicator levels. A joint test using the full covariance matrix rejects the null hypothesis that the DD estimates are all zero.

The DD estimates provide strong evidence that the MCC has changed the behavior of candidate countries. While constructing alternative explanations for our results is possible, it is also difficult; the identifying assumptions required to interpret the coefficients as casual estimates of the MCC incentive effect are relatively modest. Still, caution is warranted. Some estimated effects are negative. Many more estimates are not statistically significant. However taken in total, the results provide some supportive evidence that countries are attempting to qualify for MCA funds by improving their indicators. 


\subsection{Regression-Discontinuity Design Estimates}

To strengthen our findings, we also estimate the DD model using a narrower range of countries around the candidacy threshold of $\$ 1575$. Narrowing in on the discontinuity in this fashion borrows from the intuition of regression-discontinuity design. Unfortunately, the small number of available observations limits our ability to narrow the estimation window. Nevertheless, the more we can estimate the incentive effect based solely on the arbitrary MCC candidacy cutoff, the more we can interpret the estimate causally; there is little reason besides the MCC that countries just below the candidacy cutoff should have different reform patterns than those just above the cutoff.

Estimates that use a narrow estimation window are generally stronger, both in terms of magnitude and statistical significance, than those that use a larger sample of countries. The "conservative" columns in Table 8 report seemingly unrelated regression DD estimates of the MCC impact for individual indicators using only those countries with GNI per capita between $\$ 750$ and $\$ 2500$. Similarly, Figure 5 shows the relationship between the size of the estimation window and the DD estimate of the MCC impact on the fraction of indicators a country improves. Halving the estimation window from $\$ 3000$ to $\$ 1500$ doubles the size of the estimated effect. The statistical significance of the estimate also increases, even though the sample size falls.

Focusing on countries near the candidacy threshold changes the interpretation of the estimated coefficients. Because they are based on the set of countries near the candidacy threshold, they do not estimate of the average effect for candidate countries. If, for example, extremely poor countries have no capability to increase their indicators, then the estimated incentive effect using the narrow window will be higher than the average effect. This heterogeneity is likely if countries behave strategically and recognize they have no hope of becoming eligible.

\subsection{Other Strategies: Targeting "Incentivized" Countries}

All of the empirical strategies for estimating the MCC incentive effect described above suffer from a common flaw: they make no distinction between candidate countries that could plausibly have an incentive to improve indicator performance due to the MCC and those that could not plausibly have an incentive. While approaches that do not make this distinction are useful for estimating the average effect, they may mask important heterogeneity. In principle, a more accurate estimate of the MCC incentive effect for particular countries could be derived by comparing countries whose incentive to reform is strongest and to those that have no incentive to reform.

Despite the apparent simplicity of this approach, identifying a suitable measure for "strength of incentive" as well as an appropriate control group of countries is more complex than it first appears. Any attempt to measure the strength of incentive as a continuous variable must, by necessity, invoke strong and complicated assumptions about the relative cost of improving one indicator versus another and the probability of achieving a passing grade in each indicator group. Eschewing the continuous variable approach, one might be tempted to target only those instances in which a country would pass 
to the eligibility stage if its performance on a single indicator improved slightly. While seemingly straightforward, this approach suffers from a critical flaw: there are simply too few such observations.

Because indicators are interrelated and the eligibility cutoff is based on the median, it is difficult to exploit the discontinuities in the eligibility rule. By definition, if one country's score on an indicator rises above the median another country's must fall below the median. In some instances, such as if the country is disqualified from receiving MCA funds by pre-existing congressional mandate ${ }^{26}$ or has little chance of gaining access to funds due to poor performance on other indicators, the potentially "displaced" country may not care about its indicator falling below the median. However, the majority of countries with indicator scores lying just above the threshold do have an incentive to "defend" their score.

Countries identified as having a strong incentive to improve an indicator are also likely to differ systematically from other countries. While some country attributes such as wealth and size are easy to control for in a regression, other characteristics are not. For example, countries with a strong incentive to reform due to the presence of the MCC are, by definition, relatively high performing poor countries. Such countries may naturally attempt to correct "deficiencies" in their policy environment once they are aware of them and thus would have a tendency to improve lagging indicators regardless of the MCC. If this is the case, the approach described above would inevitably result in misleading estimates.

In earlier work, we estimated the MCC incentive effect using several strategies that relied on the eligibility rule. All proved problematic and thus are not reported here. Absent a more formal test, we checked our strategies by using only countries that should have no incentive to improve their indicators, such as candidate countries in the pre-MCC period or non-candidate countries. Even for these countries our estimates were often statistically significant, undermining the notion that the estimators could be used to consistently estimate the MCC incentive effect. ${ }^{27}$

\subsection{Are Countries Just "Gaming the System"?}

The threat of data corruption due to manipulation appears a serious one at first. Many of the MCC indicators are not only recently devised and relatively untested, but attempt to measure intangible qualities of governance. Any manipulation of indicators would fundementally alter the policy implications of our results. Yet a closer look at how each of these indicators is compiled reveals that first impressions may exaggerate this threat.

Some of the indicators, most notably those which measure civil liberties, political rights and trade policy, are simply too opaque to plausibly be subject to manipulation. Scores on these indicators are

\footnotetext{
${ }^{26}$ Although such countries do not qualify as candidates for MCA funds their indicator scores are still used to calculate the median values.

${ }^{27}$ Although we did not achieve satisfactory results, future work may prove fruitful. The eligibility rule provides and incredible amount of variation unique to the MCC. With better methods, this may allow for highly credible estimates of the MCC incentive effect.
} 
set by a panel of independent anonymous experts according to guidelines only vaguely described by the organization responsible for compiling the indicators. With little clue as to what specific aspects of governance these experts base their evaluations on, countries would be hard pressed to find an easy shortcut to a higher score.

Likewise, the indicators for inflation and fiscal policy seem similarly immune to the threat of manipulation. The incentive to distort the data when it comes to these indicators is not a recent phenomenon and the IMF has a long track record of experience in assessing the veracity of these statistics.

The five indicators compiled by the World Bank Institute, which seek to measure voice and accountability, regulatory quality, control of corruption, rule of law and government effectiveness, are less obviously immune to the threat of manipulation. Due to the vaguely defined nature of the underlying attributes which they seek to measure and the paucity of hard empirical data on which to base measurements, these indicators must, by necessity, rely on perceptions of the underlying attribute, as measured via polls and surveys, rather than the attribute itself. In theory, a country with an incentive to improve its score on one of these indicators could act to improve the perception of the attribute without actually improving the attribute itself or, worse yet, exploit weaknesses in the survey design to narrowly focus on one element of that perception which is disproportionately weighted in the overall score.

While plausible, we find it highly unlikely in practice that a country would be able to gain much from targeting the perception of a policy attribute rather than the actual attribute. Democratically elected leaders have long had a strong incentive to improve perceptions of things such as rule of law and control of corruption and citizens have long been wary of empty promises in these policy areas. Considering this, it seems probable that any easy methods of shifting perceptions of these attributes without actually altering the attributes themselves have already been attempted.

It is also unlikely that country leaders can exploit weaknesses in the design of the surveys that are used to compile the World Bank Institute indicators. This is because each of the World Bank Institute indicators is compiled using a weighted average of several different surveys where the individual weighting of each survey is inversely proportional to the estimate of the variance of the error of the survey. ${ }^{28}$ While not all surveys are conducted in all countries, for the last release of the World Bank Institute indicators in 2004, the median number of sources used to calculate the scores of each country was above 7 for all indicators and the share of countries for which there was only one source to rely was less than $10 \%$ for all indicators.

Of the remaining six indicators, three - girls' primary education completion rate, days to start a

\footnotetext{
${ }^{28}$ This means that if a small group of incentivized countries, without coordinating efforts, each targeted the survey most likely to lead to the highest gains in overall indicator score per effort expended based on the survey's weighting in the most recent compilation of the indicator score, the estimate of the variance of the error of this survey would most likely rise dramatically and thus its weighting in the overall indicator score would most likely fall dramatically as well. Thus, while such a weighting system does not guarantee that countries are not able to exploit survey weaknesses, it does ensure that without cross-country collusion, such a strategy would be maddeningly frustrating.
} 
business, and the cost of starting a business - were not included in our DD analysis due to lack of data availability. Without further knowledge about the details behind the on the ground collection of data that goes into the three other indicators - public expenditure on health, public expenditure on education, and immunization rate - we are unable to adequately assess the degree to which these indicators may be manipulated. Regrettably, vulnerability to manipulation may be the primary reason why the coefficients on these indicators are all statistically significant in our DD analysis. However while possible, we know of no reports of such manipulation.

As more data becomes available, it may be possible to test whether or not countries are manipulating the MCC indicators using more robust empirical approaches. One such approach would be to compare the performance of candidate countries on the MCC indicators with their performance on other indicators which seek to measure the same underlying attribute but which are not directly affected by efforts to increase the MCC indicators except insofar as the underlying attribute is improved. For example, to verify that the MCC is indeed causing candidate countries to improve their health care systems, we might perform a DD analysis similar to that conducted using indicators for births attended by skilled health staff, contraceptive prevalence, or diarrhea treatment rate. ${ }^{29}$ Since these indicators are unlikely to improve if candidate countries are simply overstating the amount of public money spent on health care, improvements in these indicators would provide strong corroborating evidence of the existence of an MCC incentive effect for health care.

\subsection{What is the MCC Effect's Likely Impact on Poverty Reduction?}

While we view the evidence of an MCC incentive effect as encouraging, we are reluctant to speculate how much of an effect, if any, this will have on poverty. There is simply too little evidence to suggest that the mix of policies stressed by the MCC in its selection methodology is the right one to promote poverty reduction or that such a policy mix, equally appropriate to all impoverished nations, even exists. It is also difficult to confidently interpret the magnitudes of the estimates reported. Even if the MCC does induce countries to reform and these reforms are poverty reducing, the number of such countries may be small and the size of the reforms modest.

Although perhaps to early to conduct such an analysis, Table 9 reports a DD estimate of the impact of the MCC on growth. During the pre-MCC period growth rates are low and equal in candidate and poor non-candidate countries. In the post-MCC period, growth rates rise substantially but this increase is not limited to candidate countries. The DD estimate is zero. We find no evidence that the MCC has increased growth rates in candidate countries.

This result should not be taken too seriously; any MCC affect on growth will likely take time. Considerable research, much of it using indicators that have only recently become available, suggests that high quality institutions are vital to growth, although the description of high quality is neither uniform nor unique (Rodrik, 2000; Rodrik, Subramanian and Trebbi, 2004). One of the virtues of the

\footnotetext{
${ }^{29}$ Unfortunately, due to lags in data availability, country scores on these indicators are not yet available for the year 2004.
} 
MCC criteria is that many indicators can be improved via various channels. The Kaufman governance indicators, for example, rely mostly on perceptions. While this is often considered a deficiency for research, it may be beneficial for a benchmark because it allows countries to pursue policies tailored to their particular contexts and conditions.

Regardless of the precise link between improvement in MCC indicators and poverty reduction, the indicators themselves are mostly universal goals. Health and education benchmarks, for example, are core components of the U.N. Millennium Development Goals. And poor governance often ranks as one of the top complaints of citizens in developing countries. This suggests that regardless of the poverty impact, improvement in the MCC indicators is almost certainly a desirable outcome.

\section{Conclusion}

The MCC is based on the premise that 1) aid will be more effective when given to well-governed countries and 2) countries will respond to such rewards by pursuing sound policies. While an immense empirical literature has focused on the relationship between policies and aid effectiveness, this paper is the first systematic attempt to evaluate the second claim. We seek to answer the question: can foreign aid can create an incentive for good governance? The first two years of the MCC provides a rare opportunity to study this question. By exploiting features of the MCC candidacy rules and variation before and after the MCC was created, we are able to estimate the MCC incentive effect using a simple difference-in-differences strategy. We also are able to check the robustness our estimates by exploiting the discontinuity in the MCC candidacy rule. This check borrows from the intuition of regression-discontinuity design and substantially increases our confidence that our estimates can be interpreted causally.

Even though the MCC is still in its infancy, we find substantial evidence that countries respond to MCC incentives by improving their indicators. Controlling for general time trends using poor non-candidate countries, candidate countries improve 25 percent more indicators after the MCC was created than before it - a result that is both economically and statistically significant. Treating indicators separately leads to similar results. On nine of thirteen indicators, candidate countries are more likely to improve and display larger absolute increases in the post-MCC period, again controlling for time trends using poor non-candidate countries. Moreover, most indicators appear sufficiently robust to manipulation to conclude that these estimated changes reflect real underlying policies. While still too early to make a final assessment, a range of specifications all yield supportive results.

There are also several negatives results. First, some of the anecdotal claims - such as the claim that the MCC is responsible for 80 percent candidate countries' improvement in the days to start of business indicator - do not appear robust to careful analysis. Simple comparisons that do not control for general time trends or attributes of candidate countries are unlikely to yield accurate estimates of the MCC incentive effect. Second, some of our own estimated effects are negative, and many are not statistically significant. While the results are generally positive, the evidence is not overwhelming. 
As the MCC matures and more data becomes available, further analysis will be possible. Finally, we do not find any evidence that the MCC has increased growth rates in candidate countries. This result may be due to a time lag in the effect of policy on growth, or evidence that the induced indicator improvement is not sufficient to produce economic growth.

The MCC represents the largest increase in foreign aid and the most substantial realignment of the way aid is given in forty years. While caution is warranted, our results suggest that at least one of the principles underlying the $\mathrm{MCC}$ - that aid can create an incentive for good governance - has some merit. 


\section{References}

Alesina, Alberto and Beatrice Weder. 2002. "Do Corrupt Governments Receive Less Foreign Aid?" American Economic Review 92(4):1126-1137.

Andvig, Jens Chr. 2004. "The Challenge of Poor Governance and Corruption.” NUPI Paper 665.

Angrist, J. D. and V. Lavy. 1999. "Using Maimonides' Rule to Estimate the Effect ofClass Size on Scholastic Achievement." Quarterly Journal of Economics 114(4):533-575.

Bertrand, M., E. Duflo and S. Mullainathan. 2004. "How Much Should We Trust Differences-inDifferences Estimates?” Quarterly Journal of Economics 119(1):249-275.

Burnside, Craig and David Dollar. 2000. “Aid, Policies, and Growth.” American Economic Review 90(4):847-868.

Burnside, Craig and David Dollar. 2004a. "Aid, policies, and growth : revisiting the evidence." World Bank Policy Research Working Paper 3251.

Burnside, Craig and David Dollar. 2004b. "Aid, Policies, and Growth: Reply.” The American Economic Review 94:781-784.

Dalgaard, Carl-Johan and Henrik Hansen. 2001. “On Aid, Growth and Good Policies.” Journal of Development Studies 37(6):17-41.

Easterly, William. 2003. "Can Foreign Aid Buy Growth?" Journal of Economic Perspectives 17(3):23-48.

Easterly, William, Ross Levine and David Roodman. 2004. "Aid, Policies, and Growth: Comment." American Economic Review 94(3):774-780.

Guillaumont, Patrick and Lisa Chauvet. 2001. "Aid and Performance: A Reassessment." Journal of Development Studies 37(6):66-92.

Hahn, Jinyong, Petra Todd and Wilbert Van der Klaauw. 2001. "Identification and Estimation of Treatment Effects with a Regression-Discontinuity Design.” Econometrica 69(1):201-209.

Hansen, Henrik and Finn Tarp. 2000. "Aid Effectiveness Disputed.” Journal of International Development 12(3):375-98.

Hansen, Henrik and Finn Tarp. 2001. “Aid and Growth Regression.” Journal of Development Economics 64(2):547-70.

Hoxby, Caroline M. 2000. "The Effects of Class Size on Student Achievement: New Evidence from Population Variation." Quarterly Journal of Economics 115(4):1239-1285. 
Jacob, B. A. and L. Lefgren. 2004. "Remedial education and student achievement: A regressiondiscontinuity analysis." Review of Economics and Statistics 86(1):226-244.

Kurlantzick, Joshua. 2006. “Bush’s Fake Aid.” Rolling Stone.

Lensink, Robert and Howard White. 2001. “Are There Negative Returns to Aid?” Journal of Development Studies 37(6):42-65.

Mosley, Paul, John Hodgson and Arjan Verschoor. 2004. "Aid, Poverty Reduction and the New Conditionality." The Economic Journal 114:217-243.

Radelet, Steven. 2002. "Qualifying for the Millennium Challenge Account." Center for Global Development.

Radelet, Steven. 2006. The new public finance : responding to global challenges. Oxford University Press chapter Pulling Not Pushing Reforms: Delivering Aid Through Challenge Grants, p. 510.

Rodrik, Dani. 2000. "Institutions for High-Quality Growth: What They are and How to Acquire Them.” NBER Working Paper 7540.

Rodrik, Dani, Arvind Subramanian and Francesco Trebbi. 2004. "Institutions Rule: The Primacy of Institutions Over Geography and Integration in Economic Development." Journal of Economic Growth 9(2):131.

Sautet, Frédéric, Brian Hooks and Daniel Rothschild. 2005. "The Challenge Ahead: Maintaining a Focus on Incentives to Enable Development.” Public Interest Comment on MCC FY2006 Report to Congress.

Thistlethwaite, D. and D. Campbell. 1960. "Regression-Discontinuity Analysis: An Alternative to the Ex Post Facto Experiment.” Journal of Educational Psychology 51(6):309.

van der Klaauw, Wilbert. 2002. "Estimating the Effect of Financial Aid Offers on College Enrollment: A Regression-Discontinuity Approach.” Internationl Economic Review 43(4):1249-1287.

Zellner, Arnold. 1962. "An Efficient Method of Estimating Seemingly Unrelated Regressions and Tests for Aggregation Bias." Journal of the American Statistical Association 57(298):348. 
TABLE 1. SUMMARY OF MCC INDICATORS

\begin{tabular}{lll}
\hline \hline & Indicator & Source \\
\hline & Political Rights (-) & Freedom House \\
& Civil Liberties (-) & Freedom House \\
& Voice and Accountability (+) & World Bank Institute \\
& Government Effectiveness (+) & World Bank Institute \\
& Rule of Law (+) & World Bank Institute \\
& Control of Corruption (+) & World Bank Institute \\
\hline & Girls' Primary Education Completion Rate (+) & World Bank Group and UNESCO \\
& Public Primary Education Spending (\%GDP) (+) & National Governments \\
& Public Expenditure on Health (\% GDP) (+) & National Governments \\
& Immunization Rate for DPT3 and Measles (+) & World Health Organization \\
\hline
\end{tabular}

Notes: FY2006 indicators. Signs in parentheses indicate the direction of change that is associated with an improvement. Girls primary education completion rate replaced primary education completion rate in FY005; Cost of starting a business replaced country credit rating in FY2006. The DPT3 shot provides protection against infection from diphtheria, pertussis (whooping cough) and tetanus. Cost of starting a business is expressed as a percent of per capita income. One year inflation rate is compiled from multiple sources, see MCC website for full details. 
FIGURE 1. SOURCES OF U.S. FOREIGN AID (IN BILLIONS), 2004

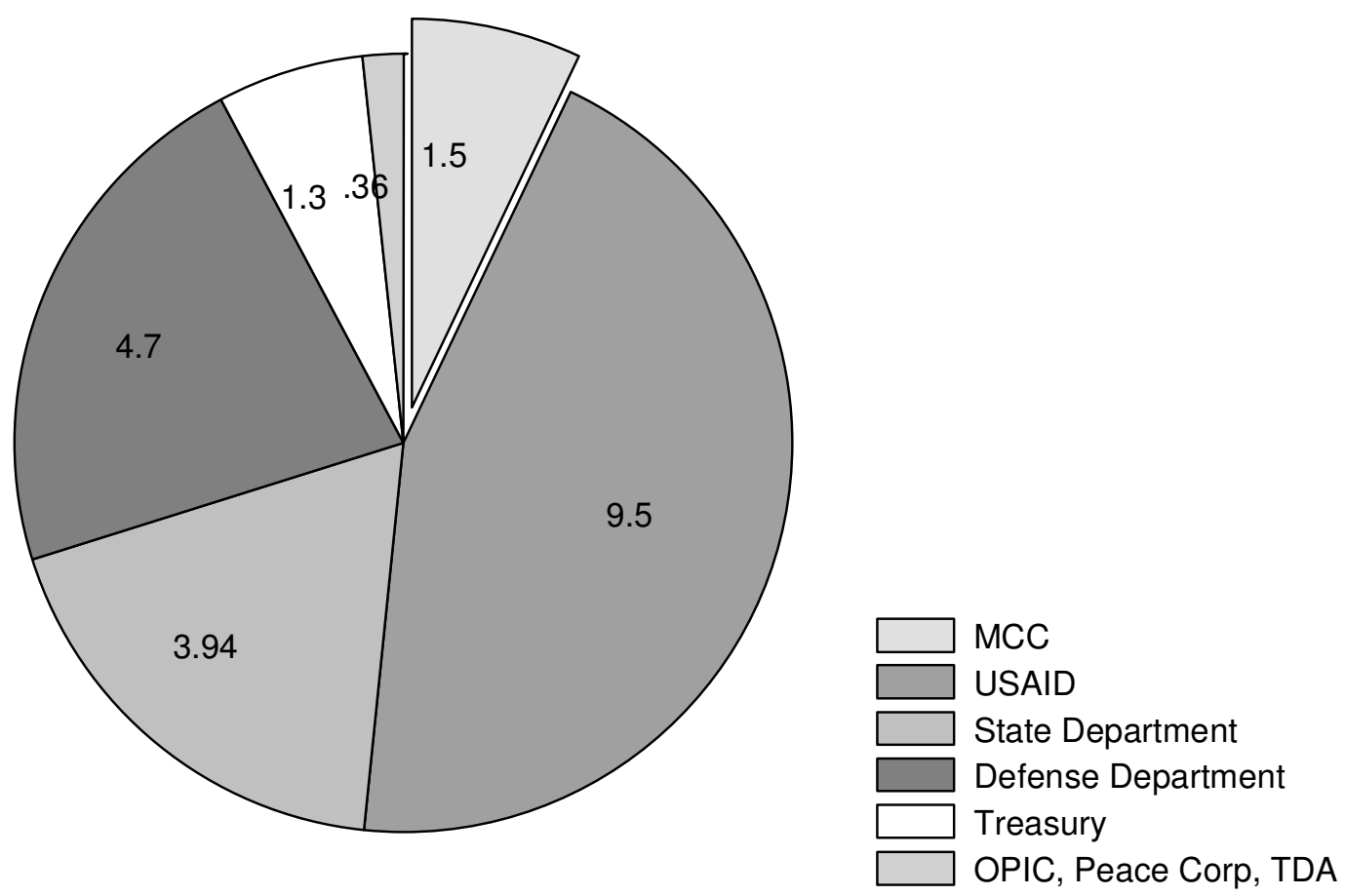

Source: CRS Report for Congress, "Foreign Aid: An Introductory Overview of US Programs and Policy", http://usinfo.state.gov/usa/infousa/trade/files/98-916.pdf 
Figure 2. MCA Aid AS A PERCENTAGe of Total Aid AND GOVERnMENT EXPENDiture

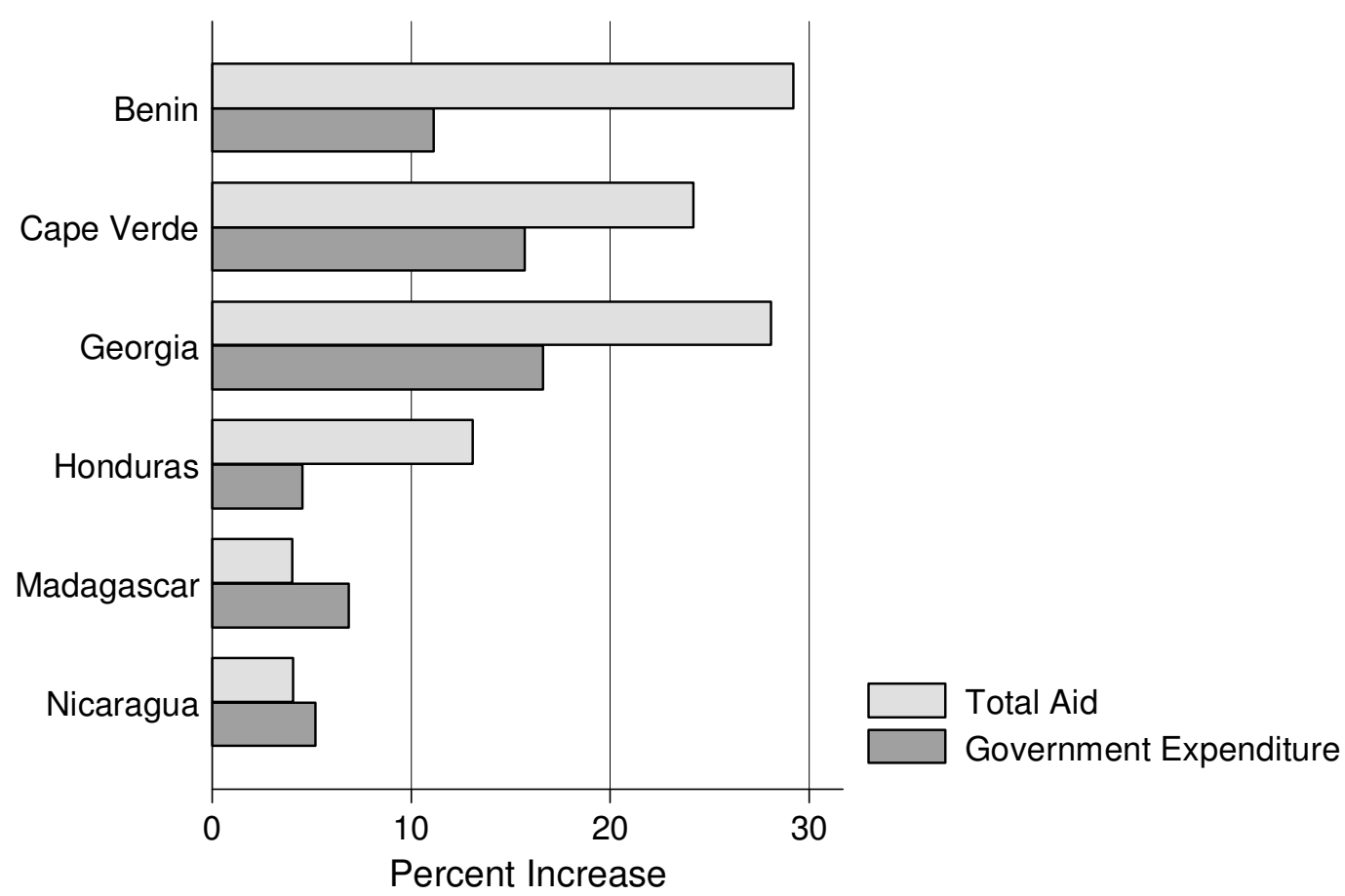

Notes: Completed compacts as of February 1, 2006. MCA aid amount calculated as Total Compact Amount / Years of Compact. Total aid and government expenditure come from OECD DAC and the World Development Indicators. 
Table 2. Top Ten Donors by Net Official DeVelopment Assistance Plus Projected AnNual Receipts From MCC for Countries with APPROVED COMPACTS

\begin{tabular}{|c|c|c|c|c|c|c|c|c|c|c|c|}
\hline \multirow{2}{*}{$\begin{array}{l}\text { Benin } \\
\text { Donor }\end{array}$} & \multirow[b]{2}{*}{ Amount } & \multicolumn{2}{|l|}{ Georgia } & \multicolumn{2}{|l|}{ Cape Verde } & \multicolumn{2}{|l|}{ Honduras } & \multicolumn{2}{|c|}{ Nicaragua } & \multicolumn{2}{|c|}{ Madagascar } \\
\hline & & Donor & Amount & Donor & Amount & Donor & Amount & Donor & Amount & Donor & Amount \\
\hline $\mathrm{EC}$ & 70 & USA & 84 & Portugal & 39 & IDB & 117 & Germany & 407 & France & 319 \\
\hline MCA & 61.4 & MCA & 59 & $\mathrm{EC}$ & 25 & USA & 91 & Spain & 142 & IDA & 273 \\
\hline France & 60 & IDA & 54 & MCA & 22 & IDA & 85 & IDA & 128 & $\mathrm{EC}$ & 109 \\
\hline IDA & 42 & Germany & 45 & IDA & 16 & Spain & 56 & IDB & 123 & USA & 42 \\
\hline USA & 30 & $\mathrm{EC}$ & 32 & Luxembourg & 11 & MCA & 43 & Japan & 89 & IMF & 34 \\
\hline Germany & 28 & Japan & 14 & Netherlands & 9 & $\mathrm{EC}$ & 37 & USA & 75 & Germany & 33 \\
\hline Denmark & 27 & $\mathrm{IMF}$ & 10 & Japan & 8 & Japan & 32 & $\mathrm{EC}$ & 57 & AfDf & 32 \\
\hline Japan & 26 & Switzerland & 7 & USA & 6 & Germany & 22 & France & 46 & MCA & 27.5 \\
\hline AfDf & 23 & Netherlands & 6 & Afdf & 6 & Sweden & 21 & Sweden & 39 & Italy & 22 \\
\hline Netherlands & 15 & Greece & 6 & Spain & 6 & IMF & 15 & $\mathrm{IMF}$ & 35 & UK & 16 \\
\hline Belgium & 12 & Norway & 5 & France & 4 & Italy & 14 & MCA & 35 & Japan & 10 \\
\hline
\end{tabular}

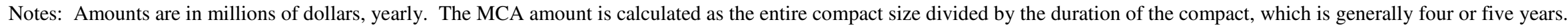
Country donor data is drawn from OECD DAC Statistics. Includes compacts completed as of February 1, 2006. 
TABLE 3. SumMary STATISTICS

LOW AND LOW-MIDDLE INCOMES COUNTRIES (2000, 2002, 2004)

\begin{tabular}{lrrrrr}
\hline \hline Indicator & Obs & Mean & Std. Dev. & \multicolumn{1}{l}{ Min } & \multicolumn{1}{c}{ Max } \\
\hline Political Rights (-) & 306 & 4.2 & 1.9 & 1.0 & 7.0 \\
Civil Liberties (-) & 306 & 4.1 & 1.4 & 1.0 & 7.0 \\
Voice and Accountability (+) & 306 & -0.5 & 0.7 & -2.1 & 1.3 \\
Government Effectiveness (+) & 306 & -0.6 & 0.5 & -1.9 & 1.5 \\
Rule of Law (+) & 306 & -0.6 & 0.5 & -1.9 & 1.1 \\
Control of Corruption (+) & 306 & -0.6 & 0.5 & -1.7 & 1.1 \\
\hline Girls Education Rate (+) & 140 & 70.8 & 28.2 & 12.2 & 110.9 \\
Education Expenditure (+) & 240 & 2.5 & 1.9 & 0.0 & 9.9 \\
Health Expenditure (+) & 285 & 2.4 & 2.1 & 0.0 & 14.8 \\
Immunization Rate (+) & 297 & 75.9 & 20.3 & 15.5 & 99.0 \\
\hline Business Start Cost (-) & 91 & 115.3 & 183.3 & 6.7 & 1268.4 \\
Inflation Rate (-) & 259 & 12.0 & 41.9 & -6.3 & 550.0 \\
Fiscal Policy (+) & 299 & -3.7 & 4.4 & -32.4 & 12.0 \\
Trade Policy (-) & 254 & 3.9 & 0.9 & 1.0 & 5.0 \\
Regulatory Quality (+) & 306 & -0.5 & 0.6 & -2.7 & 1.2 \\
Business Start Time (-) & 149 & 61.3 & 40.1 & 11.0 & 214.0 \\
\hline
\end{tabular}

Notes: Indicators are described in detail in Table 1. All countries with GNI per capita below \$3255 in 2004 (low and lower-middle income countries according to MCC definition) are included for years 2000, 2002 and 2004. There are 102 countries per year if all data is available. 
TABLE 4. DD Estimates OF THE IMPACT OF THE MCC ON THE MAGNITUDE OF INDICATOR IMPROVEMENT

\begin{tabular}{|c|c|c|c|c|c|c|c|}
\hline \multirow[b]{2}{*}{ Indicator } & \multicolumn{2}{|c|}{ Candidate Countries } & \multicolumn{2}{|c|}{ Control Countries } & \multirow{2}{*}{$\begin{array}{c}1^{\text {st }} \text { Diff } \\
\text { Pre- } \\
\text { MCC }\end{array}$} & \multirow{2}{*}{$\begin{array}{c}1^{\text {st }} \text { Diff } \\
\text { Post- } \\
\text { MCC }\end{array}$} & \multirow[b]{2}{*}{ DD } \\
\hline & $\begin{array}{l}\text { Pre- } \\
\text { MCC }\end{array}$ & $\begin{array}{l}\text { Post- } \\
\text { MCC }\end{array}$ & $\begin{array}{l}\text { Pre- } \\
\text { MCC }\end{array}$ & $\begin{array}{l}\text { Post- } \\
\text { MCC }\end{array}$ & & & \\
\hline \multirow[t]{2}{*}{ Political Rights (-) } & 0.057 & -0.014 & -0.080 & 0.040 & 0.137 & -0.054 & -0.191 \\
\hline & $(0.084)$ & $(0.099)$ & $(0.215)$ & $(0.091)$ & $(0.231)$ & $(0.134)$ & $(0.267)$ \\
\hline \multirow[t]{2}{*}{ Civil Liberties (-) } & 0.029 & -0.314 & -0.040 & -0.120 & 0.069 & -0.194 & -0.263 \\
\hline & $(0.064)$ & $(0.069)$ & $(0.108)$ & $(0.066)$ & $(0.125)$ & $(0.096)$ & $(0.158)$ \\
\hline \multirow{2}{*}{ Voice and Accountability (+) } & -0.061 & 0.008 & -0.085 & -0.008 & 0.023 & 0.017 & -0.007 \\
\hline & $(0.029)$ & $(0.025)$ & $(0.033)$ & $(0.035)$ & $(0.044)$ & $(0.043)$ & $(0.062)$ \\
\hline \multirow{2}{*}{ Government Effectiveness (+) } & -0.060 & -0.078 & -0.047 & 0.002 & -0.013 & -0.080 & -0.066 \\
\hline & $(0.034)$ & $(0.027)$ & $(0.059)$ & $(0.043)$ & $(0.068)$ & $(0.051)$ & $(0.085)$ \\
\hline \multirow[t]{2}{*}{ Rule of Law (+) } & -0.021 & -0.053 & 0.049 & -0.063 & -0.070 & 0.011 & 0.081 \\
\hline & $(0.029)$ & $(0.021)$ & $(0.074)$ & $(0.051)$ & $(0.079)$ & $(0.056)$ & $(0.097)$ \\
\hline \multirow[t]{2}{*}{ Control of Corruption (+) } & -0.050 & -0.032 & -0.135 & 0.030 & 0.084 & -0.062 & -0.146 \\
\hline & $(0.037)$ & $(0.028)$ & $(0.059)$ & $(0.035)$ & $(0.069)$ & $(0.045)$ & $(0.082)$ \\
\hline \multirow[t]{2}{*}{ Girls Education Rate (+) } & 2.194 & & 0.653 & & 1.541 & & \\
\hline & $(0.860)$ & & $(1.252)$ & & $(1.519)$ & & \\
\hline \multirow[t]{2}{*}{ Education Expenditure (+) } & 0.206 & 0.209 & 0.175 & -0.099 & 0.031 & 0.309 & 0.277 \\
\hline & $(0.108)$ & $(0.088)$ & $(0.136)$ & $(0.112)$ & $(0.173)$ & $(0.142)$ & $(0.224)$ \\
\hline \multirow[t]{2}{*}{ Health Expenditure (+) } & 0.245 & 0.148 & 0.196 & 0.289 & 0.049 & -0.141 & -0.190 \\
\hline & $(0.149)$ & $(0.118)$ & $(0.069)$ & $(0.409)$ & $(0.164)$ & $(0.426)$ & $(0.457)$ \\
\hline \multirow[t]{2}{*}{ Immunization Rate $(+)$} & 2.164 & 6.118 & 3.024 & -2.283 & -0.860 & 8.400 & 9.260 \\
\hline & $(2.474)$ & $(1.837)$ & $(3.923)$ & $(3.220)$ & $(4.638)$ & $(3.707)$ & $(5.938)$ \\
\hline \multicolumn{8}{|l|}{ Business Start Cost (-) } \\
\hline \multirow[t]{2}{*}{ Inflation Rate (-) } & -13.238 & -0.844 & -12.507 & 1.157 & -0.731 & -2.001 & -1.270 \\
\hline & $(9.243)$ & $(1.643)$ & $(6.585)$ & $(2.615)$ & (11.349) & $(3.088)$ & $(11.762)$ \\
\hline \multirow[t]{2}{*}{ Fiscal Policy (+) } & 0.241 & 0.387 & 0.520 & 0.252 & -0.280 & 0.135 & 0.414 \\
\hline & $(0.500)$ & $(0.354)$ & $(0.511)$ & $(0.247)$ & $(0.715)$ & $(0.432)$ & $(0.835)$ \\
\hline \multirow[t]{2}{*}{ Trade Policy (-) } & -0.237 & 0.105 & -0.175 & 0.333 & -0.062 & -0.228 & -0.166 \\
\hline & $(0.099)$ & $(0.089)$ & $(0.167)$ & $(0.205)$ & $(0.194)$ & $(0.224)$ & $(0.296)$ \\
\hline \multirow[t]{2}{*}{ Regulatory Quality (+) } & -0.216 & 0.051 & -0.077 & -0.029 & -0.139 & 0.080 & 0.219 \\
\hline & $(0.048)$ & $(0.030)$ & $(0.094)$ & $(0.057)$ & $(0.106)$ & $(0.065)$ & $(0.124)$ \\
\hline \multirow[t]{2}{*}{ Business Start Time (-) } & & -17.744 & & -13.250 & & -4.494 & \\
\hline & & $(3.252)$ & & (7.058) & & $(7.771)$ & \\
\hline
\end{tabular}

Notes: Cells contain the changes in indicator values. Standard errors are given in parentheses. The parentheses following the indicator name show the sign of a positive improvement, given the indicator construction. DD estimates in bold are improvements. The pre-MCC period is defined as 2000 to 2002 and the post-MCC period is 2002 to 2004. Candidate countries include any country that was a candidate between 2000 and 2004. Control countries are all non-candidate countries with GNI per capita below $\$ 3255$ in 2004; all statutorily restricted countries are excluded. See text for details about indicator definitions. 


\section{TABLE 5. DD ESTIMATES OF THE IMPACT OF THE MCC ON THE LIKELIHOOD OF INDICATOR}

IMPROVEMENT

\begin{tabular}{|c|c|c|c|c|c|c|c|}
\hline \multirow[b]{2}{*}{ Indicator } & \multicolumn{2}{|c|}{ Candidate Countries } & \multicolumn{2}{|c|}{ Control Countries } & \multirow{2}{*}{$\begin{array}{c}1^{\text {st }} \text { Diff } \\
\text { Pre- } \\
\text { MCC }\end{array}$} & \multirow{2}{*}{$\begin{array}{l}1^{\text {st }} \text { Diff } \\
\text { Post- } \\
\text { MCC }\end{array}$} & \multirow[b]{2}{*}{ DD } \\
\hline & $\begin{array}{l}\text { Pre- } \\
\text { MCC }\end{array}$ & $\begin{array}{l}\text { Post- } \\
\text { MCC }\end{array}$ & $\begin{array}{l}\text { Pre- } \\
\text { MCC }\end{array}$ & $\begin{array}{l}\text { Post- } \\
\text { MCC }\end{array}$ & & & \\
\hline \multirow[t]{2}{*}{ Political Rights } & 0.16 & 0.20 & 0.12 & 0.08 & 0.04 & 0.12 & 0.08 \\
\hline & $(0.04)$ & $(0.05)$ & $(0.07)$ & $(0.06)$ & $(0.08)$ & $(0.07)$ & $(0.11)$ \\
\hline \multirow[t]{2}{*}{ Civil Liberties } & 0.10 & 0.31 & 0.16 & 0.12 & -0.06 & 0.19 & 0.25 \\
\hline & $(0.04)$ & $(0.06)$ & $(0.07)$ & $(0.07)$ & $(0.08)$ & $(0.09)$ & $(0.12)$ \\
\hline \multirow[t]{2}{*}{ Voice and Accountability } & 0.33 & 0.51 & 0.28 & 0.56 & 0.05 & -0.05 & -0.09 \\
\hline & $(0.06)$ & $(0.06)$ & $(0.09)$ & $(0.10)$ & $(0.11)$ & $(0.12)$ & $(0.16)$ \\
\hline \multirow[t]{2}{*}{ Government Effectiveness } & 0.41 & 0.39 & 0.44 & 0.52 & -0.03 & -0.13 & -0.11 \\
\hline & $(0.06)$ & $(0.06)$ & $(0.10)$ & $(0.10)$ & $(0.12)$ & $(0.12)$ & $(0.17)$ \\
\hline \multirow[t]{2}{*}{ Rule of Law } & 0.44 & 0.39 & 0.48 & 0.36 & -0.04 & 0.03 & 0.06 \\
\hline & $(0.06)$ & $(0.06)$ & $(0.10)$ & $(0.10)$ & $(0.12)$ & $(0.11)$ & $(0.16)$ \\
\hline \multirow[t]{2}{*}{ Control of Corruption } & 0.30 & 0.49 & 0.24 & 0.52 & 0.06 & -0.03 & -0.09 \\
\hline & $(0.06)$ & $(0.06)$ & $(0.09)$ & $(0.10)$ & $(0.10)$ & $(0.12)$ & $(0.16)$ \\
\hline \multirow[t]{2}{*}{ Girls Education Rate } & 0.67 & & 0.38 & & 0.28 & & \\
\hline & $(0.07)$ & & $(0.14)$ & & $(0.16)$ & & \\
\hline \multirow[t]{2}{*}{ Education Expenditure } & 0.64 & 0.63 & 0.56 & 0.29 & 0.09 & 0.34 & 0.25 \\
\hline & $(0.07)$ & $(0.07)$ & $(0.12)$ & $(0.11)$ & $(0.14)$ & $(0.13)$ & $(0.19)$ \\
\hline \multirow{2}{*}{ Health Expenditure } & 0.60 & 0.65 & 0.64 & 0.32 & -0.04 & 0.33 & 0.37 \\
\hline & $(0.06)$ & $(0.06)$ & $(0.10)$ & $(0.11)$ & $(0.11)$ & $(0.13)$ & $(0.17)$ \\
\hline \multirow[t]{2}{*}{ Immunization Rate } & 0.60 & 0.69 & 0.57 & 0.35 & 0.03 & 0.34 & 0.32 \\
\hline & $(0.06)$ & $(0.06)$ & $(0.11)$ & $(0.10)$ & $(0.13)$ & $(0.12)$ & $(0.17)$ \\
\hline \multicolumn{8}{|l|}{ Business Start Cost } \\
\hline \multirow[t]{2}{*}{ Inflation Rate } & 0.50 & 0.56 & 0.70 & 0.36 & -0.20 & 0.19 & 0.39 \\
\hline & $(0.07)$ & $(0.07)$ & $(0.10)$ & $(0.10)$ & $(0.12)$ & $(0.13)$ & $(0.17)$ \\
\hline \multirow[t]{2}{*}{ Fiscal Policy } & 0.43 & 0.65 & 0.54 & 0.63 & -0.11 & 0.02 & 0.13 \\
\hline & $(0.06)$ & $(0.06)$ & $(0.10)$ & $(0.10)$ & $(0.12)$ & $(0.12)$ & $(0.17)$ \\
\hline \multirow[t]{2}{*}{ Trade Policy } & 0.46 & 0.19 & 0.40 & 0.19 & 0.06 & 0.00 & -0.05 \\
\hline & $(0.07)$ & $(0.05)$ & $(0.11)$ & $(0.09)$ & $(0.13)$ & $(0.10)$ & $(0.17)$ \\
\hline \multirow[t]{2}{*}{ Regulatory Quality } & 0.21 & 0.50 & 0.32 & 0.32 & -0.11 & 0.18 & 0.29 \\
\hline & $(0.05)$ & $(0.06)$ & $(0.10)$ & $(0.10)$ & $(0.11)$ & $(0.11)$ & $(0.16)$ \\
\hline \multirow[t]{2}{*}{ Business Start Time } & & 0.85 & & 0.81 & & 0.03 & \\
\hline & & $(0.06)$ & & $(0.10)$ & & $(0.12)$ & \\
\hline
\end{tabular}

Notes: Cells contain the fraction of countries that improved their indicator over a two year period. Standard errors are given in parentheses. DD estimates in bold are positive estimates. The pre-MCC period is defined as 2000 to 2002 and the postMCC period is 2002 to 2004. Candidate countries include any country that was a candidate between 2000 and 2004 . Control countries are all non-candidate countries with GNI per capita below $\$ 3255$ in 2004; all statutorily restricted countries are excluded. See text for details about indicator definitions. 
TABLE 6. SUMMARY OF DD ESTIMATES FOR SEPARATE INDICATORS

\begin{tabular}{|c|c|c|c|c|c|}
\hline & \multicolumn{2}{|c|}{$\begin{array}{l}\text { More Reform post-MCC } \\
\text { than pre-MCC }\end{array}$} & \multicolumn{2}{|c|}{$\begin{array}{c}\text { Candidate Countries better than } \\
\text { Control Countries }\end{array}$} & \multirow[b]{2}{*}{$\mathrm{DD}$} \\
\hline & $\begin{array}{l}\text { Candidate } \\
\text { Countries }\end{array}$ & $\begin{array}{c}\text { Control } \\
\text { Countries } \\
\end{array}$ & Pre-MCC & Post-MCC & \\
\hline Magnitude & $8 / 13$ & $6 / 13$ & $7 / 14$ & $11 / 14$ & $9 / 13$ \\
\hline Likelihood & $9 / 13$ & $4 / 13$ & $7 / 14$ & $11 / 14$ & $9 / 13$ \\
\hline
\end{tabular}

Notes: This table summarizes Table 4 and 5. The cells contain the number of indicators in which the statement is true divided by the total number of indicators. For example, the first cell, 8/13, shows that on 8 of 13 indicators candidate countries improved their indicators faster, on average, after the MCC was created than before it. The third data cell in the second row, 7/14, shows that on 7 of 14 indicators candidate countries were more likely to improve their indicators than poor non-candidate countries, pre-MCC.

\section{FIGURE 3. FRACTION OF COUNTRIES IMPROVING INDICATOR COMPARING CANDIDATE AND CONTROL COUNTRIES BEFORE AND AFTER THE MCC WAS ESTABLISHED}
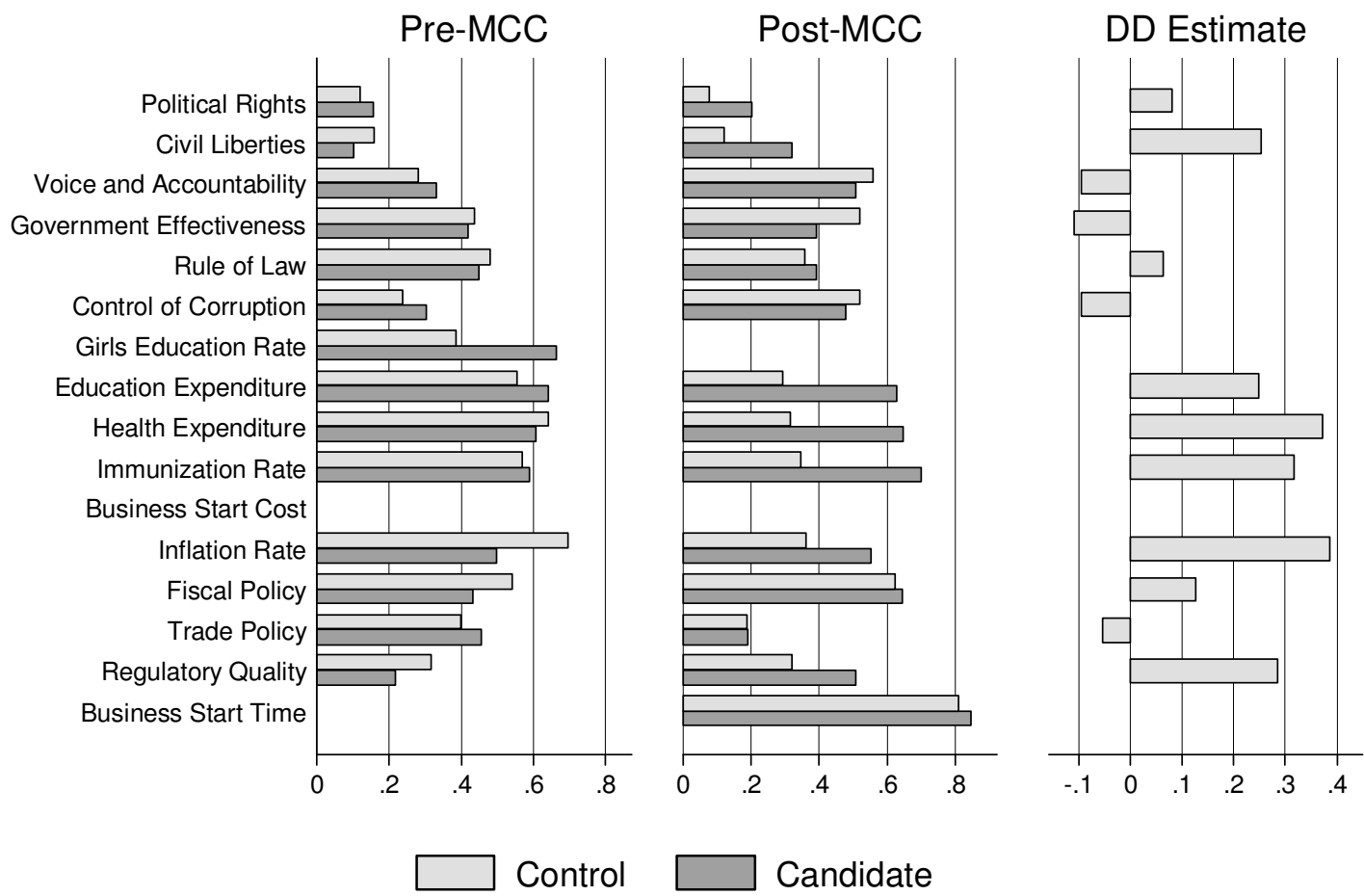

Notes: The $\mathrm{x}$-axis is the fraction of countries that improved their indicator over a two year period. Candidate countries include any country that was a candidate between 2000 and 2004. Control countries are all non-candidate countries with GNI per capita below $\$ 3255$ in 2004; all statutorily restricted countries are excluded. The pre-MCC period is defined as 2000-2002 and the post-MCC period as 2002-2004. The DD estimate subtracts the pre-MCC difference between candidate and control countries for the post-MCC difference. 
FIGURE 4. THE FRACTION OF INDICATORS A COUNTRY IMPROVED COMPARING CANDIDATE AND CONTROL CONTROLS BEFORE AND AFTER THE MCC

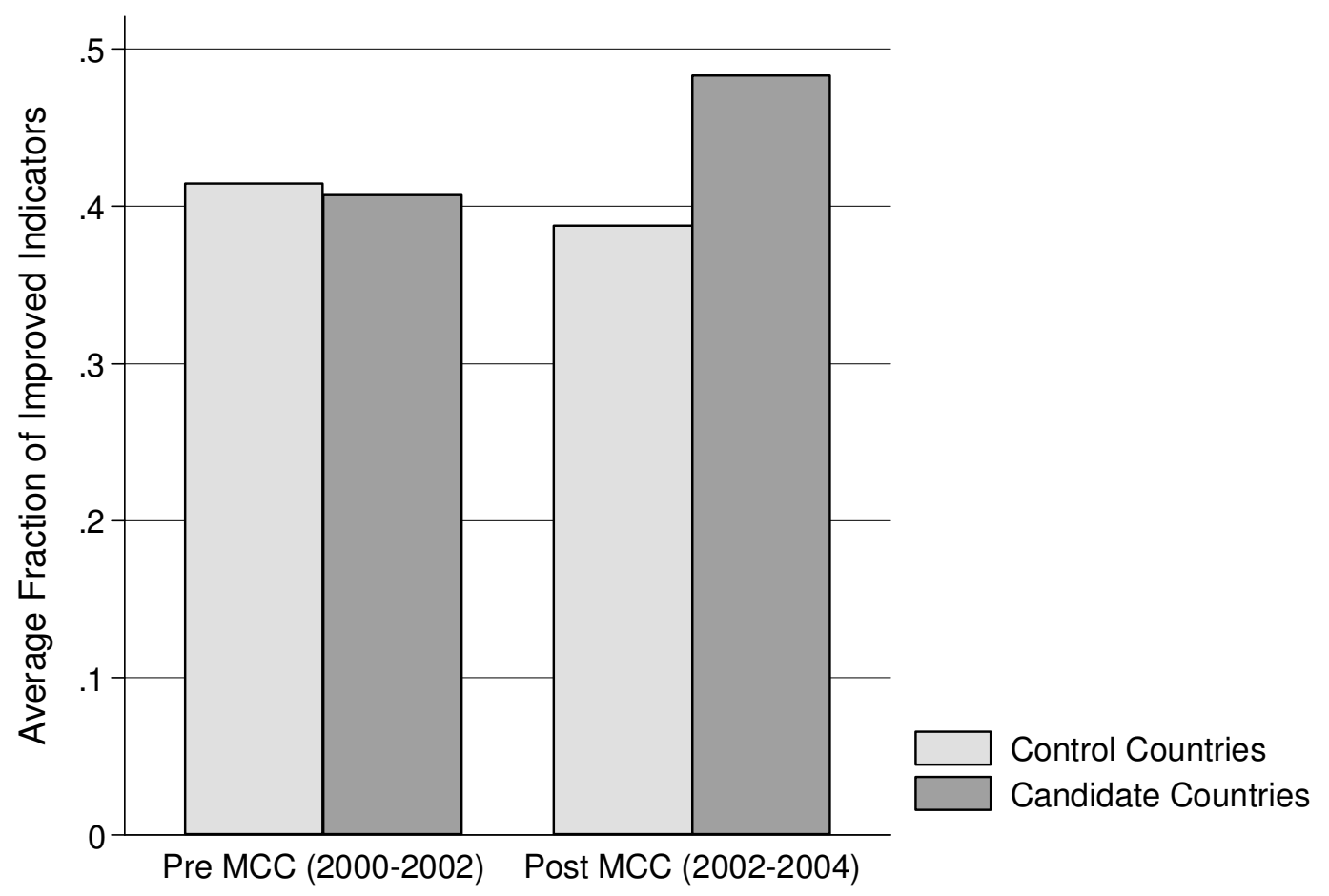

Notes: The y-axis is the mean of the fraction of indicators a country reforms over a two year period. Candidate countries include any country that was a candidate between 2000 and 2004. Control countries are all non-candidate countries with GNI per capita below $\$ 3255$ in 2004; all statutorily restricted countries are excluded. The pre-MCC period is defined as 2000-2002 and the post-MCC period as 2002-2004. 
TABLE 7. DD ESTIMATES OF THE IMPACT OF THE MCC ON THE FRACTION OF INDICATORS A COUNTRY IMPROVES OVER TWO YEARS

\begin{tabular}{lccc}
\hline \hline \multirow{2}{*}{ Country } & $\begin{array}{c}\text { Pre- } \\
\text { MCC }\end{array}$ & $\begin{array}{c}\text { Post- } \\
\text { MCC }\end{array}$ & $\begin{array}{c}\text { Time difference } \\
\text { for countries }\end{array}$ \\
\hline Candidates & 0.41 & 0.48 & 0.08 \\
& $(0.02)$ & $(0.02)$ & $(0.03)$ \\
& {$[69]$} & {$[69]$} & \\
Controls & 0.41 & 0.39 & -0.03 \\
& $(0.03)$ & $(0.03)$ & $(0.04)$ \\
\cline { 1 - 3 } Country difference at a point in time & {$[25]$} & {$[25]$} & \\
& -0.01 & 0.10 & \\
Difference-in-Difference & $(0.04)$ & $(0.04)$ & \\
\cline { 2 - 3 } & \multicolumn{3}{c}{$\mathbf{0 . 1 0}$} \\
\hline
\end{tabular}

Notes: Cells contain the mean fraction of indicators a country has improved over a two year period. Standard errors are given in parentheses; sample sizes are given in square brackets. The pre-MCC period is defined as 2000 to 2002 and the post-MCC period is 2002 to 2004 . Candidate countries include any country that was a candidate between 2000 and 2004. Control countries are all non-candidate countries with GNI per capita below $\$ 3255$ in 2004; all statutorily restricted countries are excluded. 
FIGURE 5. OLS DD ESTIMATES OF THE MCC IMPACT ON THE FRACTION OF INDICATORS A COUNTRY IMPROVES OVER TWO YEARS, VARYING THE SIZE OF THE ESTIMATION WINDOW AROUND THE CANDIDACY CUTOFF OF \$1575 GNI PER CAPITA

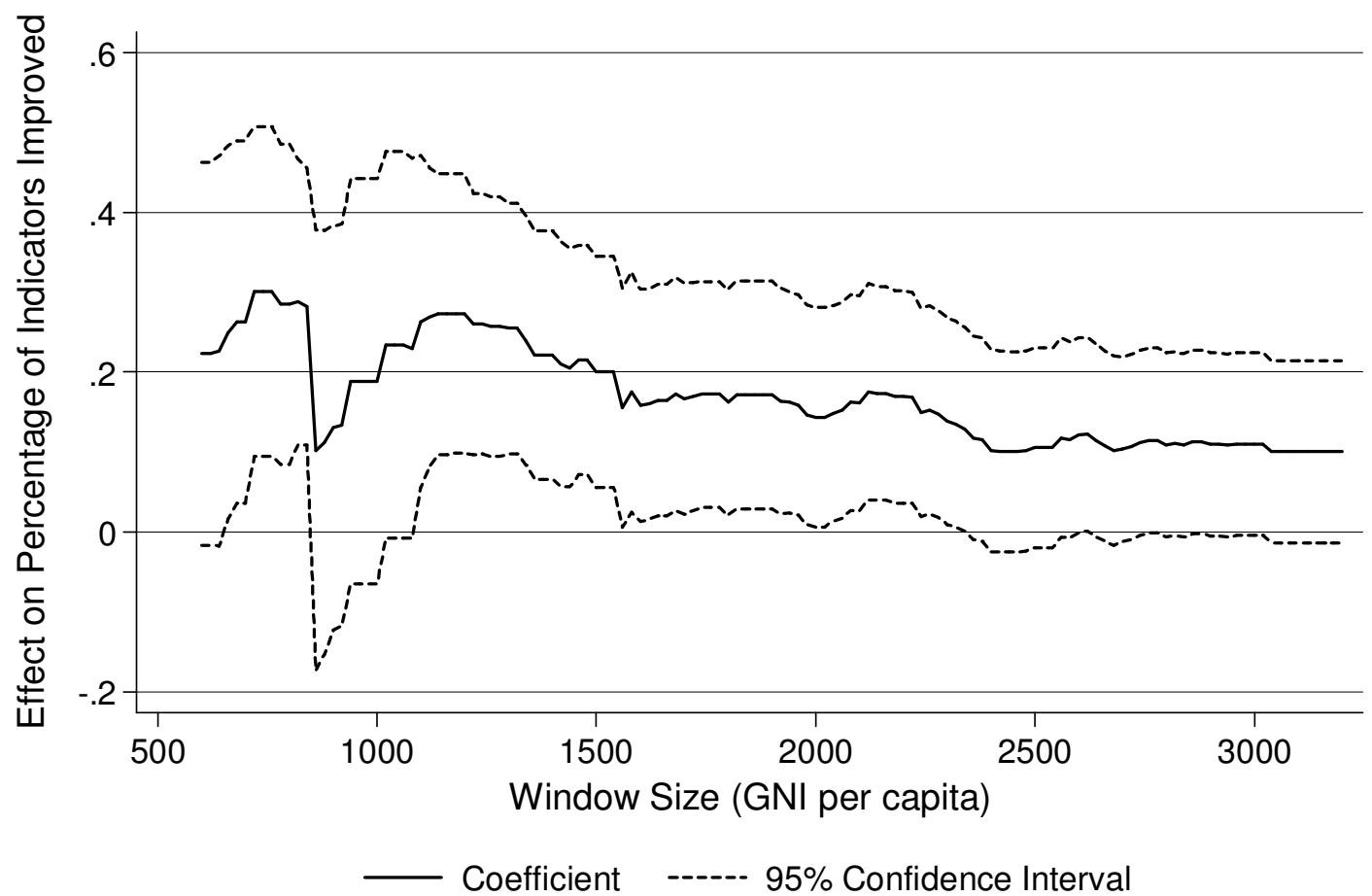

Notes: The coefficient is the interaction in equation (1), with log GNI per capita and log population included as controls. The coefficient is a DD estimate of the MCC impact on the fraction of indicators a country improves. The $\mathrm{x}$ axis is the size of the estimation window used. It is centered on the $\$ 1575$ GNI per capita cutoff that determines candidacy. For an adequate number of observations, the window must be at least $\$ 500$ wide. The confidence interval is computed using heteroskedastic-consistent standard errors. 
TABLE 8. SEEMINGLY UNRELATED REGRESSION ESTIMATES OF MCC IMPACT ON MAGNITUdE AND LIKELIHOOD OF IMPROVEMENT

\begin{tabular}{lcccc}
\hline \hline & \multicolumn{2}{c}{ Liberal } & \multicolumn{2}{c}{ Conservative } \\
& Magnitude & Likelihood & Magnitude & Likelihood \\
\hline Political Rights (-) & $\mathbf{- 0 . 6 5}$ & $\mathbf{0 . 1 9}$ & $\mathbf{- 1 . 1 7}$ & $\mathbf{0 . 2 3}$ \\
& $(0.40)$ & $(0.19)$ & $(0.58)$ & $(0.23)$ \\
Civil Liberties (-) & $\mathbf{- 0 . 5 8}$ & $\mathbf{0 . 7 5}$ & $\mathbf{- 0 . 7 2}$ & $\mathbf{0 . 7 1}$ \\
& $(0.25)$ & $(0.19)$ & $(0.26)$ & $(0.22)$ \\
Voice and Accountability (+) & $\mathbf{0 . 0 5}$ & 0.00 & $\mathbf{0 . 0 4}$ & -0.36 \\
& $(0.09)$ & $(0.23)$ & $(0.12)$ & $(0.33)$ \\
Government Effectiveness (+) & $\mathbf{0 . 0 2}$ & $\mathbf{0 . 1 3}$ & -0.04 & $\mathbf{0 . 2 5}$ \\
& $(0.10)$ & $(0.22)$ & $(0.13)$ & $(0.33)$ \\
Rule of Law (+) & -0.04 & $\mathbf{0 . 0 3}$ & $\mathbf{0 . 2 1}$ & $\mathbf{0 . 6 7}$ \\
& $(0.09)$ & $(0.23)$ & $(0.11)$ & $(0.28)$ \\
Control of Corruption (+) & -0.03 & -0.07 & $\mathbf{0 . 0 5}$ & $\mathbf{0 . 3 9}$ \\
& $(0.12)$ & $(0.23)$ & $(0.11)$ & $(0.33)$ \\
\hline Education Expenditure (+) & $\mathbf{0 . 5 2}$ & $\mathbf{0 . 3 2}$ & $\mathbf{0 . 2 0}$ & $\mathbf{0 . 9 3}$ \\
Health Expenditure (+) & $(0.29)$ & $(0.24)$ & $(0.37)$ & $(0.33)$ \\
& $\mathbf{0 . 3 5}$ & $\mathbf{0 . 5 7}$ & $\mathbf{0 . 3 5}$ & $\mathbf{1 . 1 9}$ \\
Immunization Rate (+) & $(0.25)$ & $(0.23)$ & $(0.40)$ & $(0.31)$ \\
& $\mathbf{1 0 . 6 3}$ & -0.11 & $\mathbf{9 . 5 2}$ & -0.28 \\
Inflation Rate (-) & $(6.55)$ & $(0.20)$ & $(10.93)$ & $(0.31)$ \\
Fiscal Policy (+) & -6.49 & $\mathbf{0 . 5 2}$ & $\mathbf{- 1 6 . 3 1}$ & $\mathbf{0 . 4 1}$ \\
Trade Policy (-) & $(3.28)$ & $(0.21)$ & $(5.39)$ & $(0.29)$ \\
Regulatory Quality (+) & $\mathbf{0 . 3 1}$ & $\mathbf{0 . 3 0}$ & $\mathbf{1 . 9 9}$ & $\mathbf{0 . 0 7}$ \\
& $(1.14)$ & $(0.22)$ & $(0.86)$ & $(0.31)$ \\
Observations & $\mathbf{0 . 2 0}$ & $\mathbf{0 . 1 7}$ & $\mathbf{- 0 . 5 8}$ & $\mathbf{0 . 3 1}$ \\
& $(0.31)$ & $(0.22)$ & $(0.39)$ & $(0.28)$ \\
& $\mathbf{0 . 2 6}$ & $\mathbf{0 . 3 6}$ & $\mathbf{0 . 1 5}$ & $\mathbf{0 . 1 7}$ \\
& $(0.12)$ & $(0.20)$ & $(0.15)$ & $(0.29)$ \\
\hline & 100 & 100 & 39 & 39 \\
& 0.00 & 0.00 & 0.00 & 0.00 \\
& 0.08 & 0.00 & 0.01 & 0.00 \\
\hline & & & & \\
& & & & \\
& & & & \\
& & &
\end{tabular}

Notes: The dependent variable is change in the indicator or a dummy if the indicator improved over a two year period. Standard errors are given in parentheses. Bold indicates an improvement, given the indicator construction. The regression controls for log population and 3rd degree polynomials in the starting indicator value and log GNI per capita. Days to start a business, cost of starting a business and girls primary completion rate are dropped from the regression due to insufficient observations. The coefficients reported are the interaction between the post and treatment variable, the DD estimate of the MCC effect. Post is defined as 2002-2004 and treatment is defined as candidate countries. The liberal sample is limited to countries with GNI per capita below $\$ 3255$. The conservative includes only countries with GNI per capita between $\$ 750$ and $\$ 2500$. All statutorily restricted countries are excluded. Zellner's seemingly unrelated regression is used to allow for joint tests in the presence of covariance in the error term of each regression. The likelihood specification is a linear probability model and the coefficient can thus be greater than one. The Breusch-Pagen test indicates that covariance exists across indicators. The joint test is for all the interaction coefficients equaling zero. 
TABLE 9. DD ESTIMATES OF THE IMPACT OF THE MCC ON GROWTH

\begin{tabular}{|c|c|c|c|}
\hline Country & $\begin{array}{l}\text { Pre- } \\
\text { MCC }\end{array}$ & $\begin{array}{l}\text { Post- } \\
\text { MCC }\end{array}$ & $\begin{array}{l}\text { Time difference } \\
\text { for countries }\end{array}$ \\
\hline \multirow[t]{3}{*}{ Candidates } & 0.01 & 0.11 & 0.11 \\
\hline & $(0.01)$ & $(0.01)$ & $(0.01)$ \\
\hline & 69 & 69 & \\
\hline \multirow[t]{3}{*}{ Controls } & 0.00 & 0.11 & 0.11 \\
\hline & $(0.01)$ & $(0.02)$ & $(0.02)$ \\
\hline & 25 & 25 & \\
\hline \multirow[t]{2}{*}{ Country difference at a point in time } & 0.00 & 0.00 & \\
\hline & $(0.01)$ & $(0.02)$ & \\
\hline \multirow[t]{2}{*}{ Difference-in-Difference } & \multirow{2}{*}{\multicolumn{2}{|c|}{$\begin{array}{c}0.00 \\
(0.02)\end{array}$}} & \\
\hline & & & \\
\hline
\end{tabular}

Notes: Cells contain the yearly growth rate, computed over two years: [ln(GNI per capita $\mathrm{t}_{\mathrm{t}}$ $\ln \left(\right.$ GNI per capita $\left.\left._{\mathrm{t}-2}\right)\right] / 2$. Standard errors are given in parentheses; sample sizes are given in square brackets. The pre-MCC period is defined as 2000 to 2002 and the post-MCC period is 2002 to 2004. Candidate countries include any country that was a candidate between 2000 and 2004. Control countries are all non-candidate countries with GNI per capita below $\$ 3255$ in 2004; all statutorily restricted countries are excluded. 

Completed Compact
Eligible Countries
Ineligible Countries

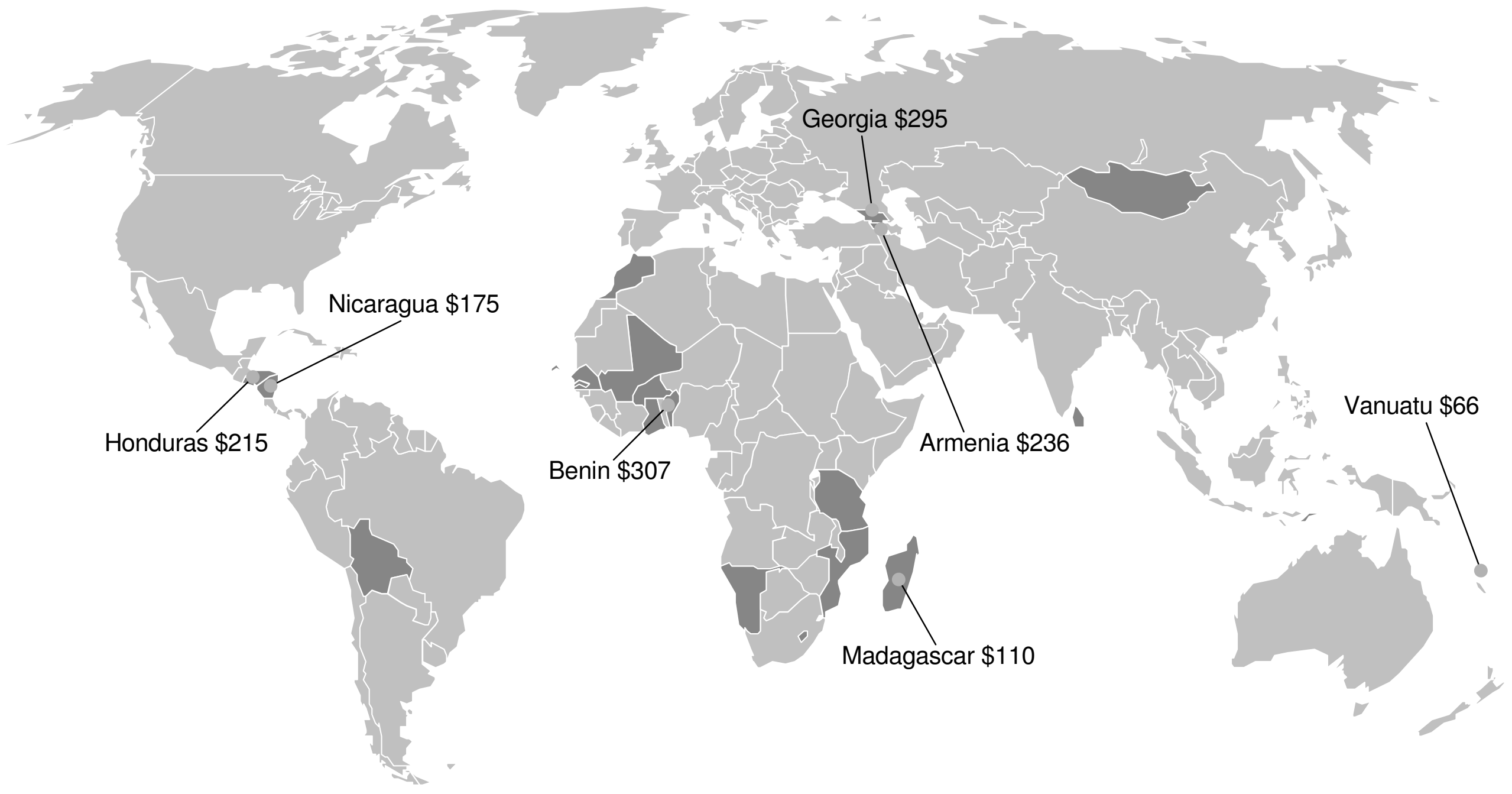

